\title{
Non-Covalent PS-SC-PI Triblock Terpolymers via Polylactide Stereocomplexation: Synthesis and Thermal Properties
}

\author{
Viko Ladelta, Konstantinos Ntetsikas, George Zapsas, and Nikos Hadjichristidis*
}

Cite This: https://doi.org/10.1021/acs.macromol.1c02294

Read Online

ABSTRACT: Polylactide (PLA) stereocomplexes (SCs) containing amorphous block copolymers have gained enormous interest due to their unique properties and wide range of potential applications. In this work, we report the synthesis and properties of non-covalent triblock terpolymers: polystyrene-SCPLA-polyisoprene (PS-SC-PI) via the stereocomplexation of PS- $b$-PDLA with PI- $b$-PLLA diblock copolymers through the solutionprecipitation method. The diblock copolymers were prepared by combining the anionic polymerization high-vacuum technique with

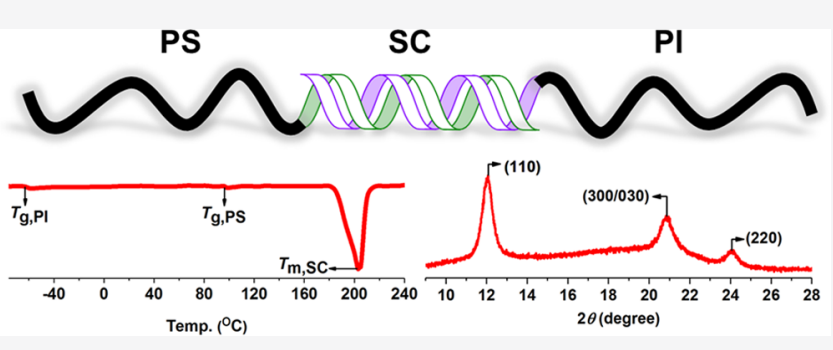
ring-opening polymerization (ROP). First, several well-defined $\omega$-hydroxyl polystyrenes and polyisoprenes (PS-OH and PI-OH) with varied molecular weights were synthesized by anionic polymerization using sec-BuLi as the initiator. PS-OH and PI-OH were used as the macroinitiators for the ROP of DLA and LLA catalyzed by tin(II) 2-ethyl hexanoate to afford PS- $b$-PDLA and PI- $b$ PLLA. PS-SC-PIs were prepared by mixing PS- $b$-PDLA and PI- $b$-PLLA solutions (in dichloromethane) and precipitated into methanol. The molecular characteristics of the block copolymers were determined by ${ }^{1} \mathrm{H}$ NMR spectroscopy and size exclusion chromatography. The formation of PS-SC-PIs was evidenced by differential scanning calorimetry, X-ray diffraction, and Fouriertransform infrared, and circular dichroism spectroscopies. A preliminary study by atomic force microscopy reveals the thin-film phase behavior and the supramolecular organization of the PS-SC-PI.

\section{INTRODUCTION}

Polylactides (PLAs) have attracted significant attention in the past few decades due to their outstanding thermal and mechanical properties, biodegradability, and biocompatibility. ${ }^{1-4}$ PLAs have been widely used as biodegradable plastics, as nanocarriers in drug delivery, in tissue engineering, and in 3D printing, among other applications. ${ }^{5-8}$

PLAs can be prepared by ring-opening polymerization (ROP) of lactide (LA). ${ }^{9}$ One of the most common catalysts for ROP of LAs is tin(II) 2-ethyl hexanoate $\left(\mathrm{Sn}(\mathrm{Oct})_{2}\right)$, which can catalyze the ROP of LAs in bulk or solutions. $\mathrm{Sn}(\mathrm{Oct})_{2}$ is widely used as the catalyst for ROP of LAs and lactones because it is cheap, commercially available, has good solubility in organic solvents, is stable at high temperature, and promotes a well-controlled ROP with a high degree of stereoregularity. ${ }^{10}$ Moreover, $\mathrm{Sn}(\mathrm{Oct})_{2}$ has been approved as a food additive by the FDA. ${ }^{9}$

LAs possess two stereocenters and thus provide three stereoisomeric forms: $(R, R)$ L-lactide (LLA), $(S, S)_{D}$-lactide (DLA), and $(R, S)$ meso-lactide $(m \mathrm{LA}) .{ }^{11}$ The polymerization of LLA or DLA with $\mathrm{Sn}(\mathrm{Oct})_{2}$ leads to the formation of poly(L-lactide) (PLLA) and poly(D-lactide) (PDLA) with a high degree of isotacticity. Isotactic PLLA and PDLA undergo a stereoselective association to form a PLA stereocomplex (SC) in melt or solution. ${ }^{11,12}$ Stereocomplexation of PLAs has gained significant interest in material science because the resulting SC has improved mechanical and thermal properties compared with the corresponding homopolymers. ${ }^{13}$

A SC was first reported in 1987 by Ikada et al., who used differential scanning calorimetry (DSC) and wide-angle X-ray diffraction to study the stereocomplexation of PLLA and PDLA blends with different molar ratios. ${ }^{14}$ Ozaki et al. found that SC crystallites are stabilized by the intermolecular hydrogen bonding $\left(\mathrm{CH}_{3} \cdots \mathrm{O}=\mathrm{C}\right)$ of the two opposite homochiral PLA chains, forming a more dense polymeric packing compared to homochiral crystallites. ${ }^{15,16}$

Stereocomplexation of an equimolar mixture of PLLA with PDLA homopolymers produces polymeric materials exhibiting a completely new crystalline structure (triangular instead of orthorhombic crystal lattice). ${ }^{17,18}$ The resulting SC-based PLA materials show improved mechanical properties as well as higher thermal and hydrolytic stability. These enhanced thermo-mechanical properties result from the hydrogen bonding interaction between $\mathrm{L}^{-}$and D-lactides in the PLA SCs. ${ }^{19-23}$

Received: November 6, 2021

Revised: January 26, 2022 
In order to improve their properties and expand their applications, PLAs have been copolymerized with many other polymers, resulting in new polymeric materials. ${ }^{24}$ The presence of another polymeric block covalently linked to the PLA segment has been used to improve the thermal and mechanical properties and derive a new morphological behavior. The selfassembly of PLA-containing block copolymers has created pathways for the fabrication of various nanoparticles with optimized properties, advanced drug carriers, and drug release systems and led to the invention of new morphologies. $1,9,25$ Several polymers that have been block copolymerized with PLAs including polyethylene glycol (PEG), ${ }^{26-33}$ poly $(\varepsilon$ caprolactone) (PCL), ${ }^{34}$ polymenthide, ${ }^{35,36}$ poly(butylene succinate), ${ }^{37}$ poly(2-(dimethylamino)ethyl methacrylate), polyacrylic acid (PAA), ${ }^{38-42}$ poly(3-hexyl thiophene) (P3HT), ${ }^{23}$ polystyrene $(\mathrm{PS})^{43}$ and polyisoprene $(\mathrm{PI}) .^{24,44,45}$

Furthermore, several studies have been reported on the synthesis and application of non-covalent triblock copolymers based on PLA SCs. Some examples are PEG-SC-PEG, ${ }^{27,28}$ P3HT-SC-P3HT, ${ }^{23}$ PDMAEMA-SC-PDMAEMA, ${ }^{38,40}$ PCL-SC-PCL, ${ }^{34} \mathrm{PAA}-\mathrm{SC}-\mathrm{PAA},{ }^{46}$ and PDMS-SCPDMS. $^{24}$ Nevertheless, to the best of our knowledge, there is no report on the synthesis and properties of non-covalent polystyrene-SCPLA-polyisoprene (PS-SC-PI) triblock terpolymers.

Ho and co-workers synthesized a PS- $b$-PLA diblock copolymer via the combination of nitroxide-mediated polymerization (NMP) and ROP. ${ }^{47}$ PS was first prepared by the NMP of styrene initiated with benzyl peroxide using 2,2,6,6tetramethylpiperidine 1-oxyl, 2,2,6,6-tetramethyl-1-piperidinyloxy (TEMPO) as the radical mediator. The resulting 4hydroxy-TEMPO-PS was mixed with $\left[\left(\mu_{3}-\mathrm{EDBP}\right) \mathrm{Li}_{2}\right]_{2}\left[\left(\mu_{3^{-}}\right.\right.$ $\left.n \mathrm{Bu}) \mathrm{Li}\left(0.5 \mathrm{Et}_{2} \mathrm{O}\right)\right]_{2}$ to form a lithium alkoxide macroinitiator. The resulting diblock copolymer was studied extensively to understand the chiral properties of the diblock copolymers, the self-assembly of the nano-helices, and the formation of nanoreactor. ${ }^{48-51}$ On the other hand, Yamanobe et al. studied the formation of the SC crystal of PS-PLLA with PDLA as well as the self-assembly and phase separation of the block copolymer. ${ }^{43}$ The obtained SC crystal exhibited a maximum achievable $T_{\mathrm{m}}$ at $245{ }^{\circ} \mathrm{C}$. Moreover, they found that double melting endotherms are characteristic for these blends, where reorganization of SC crystals occurs during heating scans.

On the other hand, Hillmyer and co-workers synthesized PI$b$-PLA by combining anionic polymerization and ROP. An $\omega$ hydroxyl-terminated PI (PI-OH) macroinitiator was prepared by the anionic polymerization of isoprene followed by an endfunctionalization with ethylene oxide (EO) and termination with acidic methanol. ${ }^{44,45}$ The PI-OH was used as a macroinitiator to promote the ROP of $m L A$ and LLA for the preparation of model PI- $b$-PLA diblock copolymers. Furthermore, they synthesized polylactide- $b$-polyisoprene- $b$-polylactide (PLA- $b$-PI- $b$-PLA) triblock copolymers by using 1-tertbutyldimethylsiloxypropyllithium as the initiator followed by deprotection of the silyl group to afford $\alpha, \omega$-dihydroxy polyisoprene (HO-PI-OH). HO-PI-OH was used as a macroinitiator to initiate the ROP of LLA using $\mathrm{Al}(\mathrm{O}-i-\mathrm{Pr})_{3}$ as the catalyst. ${ }^{45}$

Our group recently reported the synthesis and properties of non-covalent (supramolecular) diblock copolymers based on well-defined PS and PI functionalized with hydrogen bonding motifs. $^{52}$ The driving force for the formation of the supramolecular copolymers is the donor-acceptor hydrogen bonding interaction at the $\omega$-end of the PS and PI. The supramolecular block copolymers showed interesting morphologies, different from the corresponding covalent diblock copolymers in terms of the $d$-spacings and the microdomain size and shape.

In this work, we aim to synthesize well-defined PS-SC-PI through the stereocomplexation of PI- $b$-PLLA and PS- $b$ PDLA. The synthesis of the well-defined diblock copolymers was achieved through the combination of anionic polymerization with the ROP of LAs. $\omega$-Hydroxyl functionalized PI and PS were synthesized by the anionic polymerization highvacuum technique and then used as the macroinitiators to promote the ROP of D/L-LA catalyzed by $\mathrm{Sn}(\mathrm{Oct})_{2}$. The molecular characteristics of the resulting PI- $b$-PLLA and PS- $b$ PDLA block copolymers were determined by ${ }^{1} \mathrm{H}$ nuclear magnetic resonance (NMR) spectroscopy and gel permeation chromatography (GPC). The stereocomplexation of PI- $b$ PLLA and PS- $b$-PDLA was performed by mixing PS- $b$-PDLA and PI- $b$-PLLA solutions (in dichloromethane) and precipitating it into methanol. DSC, X-ray diffraction (XRD), circular dichroism (CD), and Fourier-transform infrared (FT-IR) spectroscopies were used to prove the formation of PS-SCPI. A preliminary study by atomic force microscopy (AFM) reveals the thin-film phase behavior and the supramolecular organization of the final PS-SC-PI non-covalent triblock terpolymer. Since, on the one hand, PLAs find different applications in biomedicine and, on the other hand, the heart of the material properties is situated at the molecular level, it will be very important to synthesize and study the properties of new non-covalent SC-based biodegradable materials with different structures (stars, combs, cyclics, etc.).

\section{EXPERIMENTAL SECTION}

Materials. For Anionic Polymerization. Benzene (Sigma-Aldrich, 99\%) was purified over $\mathrm{CaH}_{2}$ and subsequently distilled and stored into a glass cylinder containing living $\mathrm{PS}^{-} \mathrm{Li}^{+}$under a high vacuum. Styrene (Sigma-Aldrich, 99\%) was purified by successive distillations over $\mathrm{CaH}_{2}$ and di- $n$-butylmagnesium (Sigma-Aldrich, $1 \mathrm{M}$ solution in heptane) and stored at $-20{ }^{\circ} \mathrm{C}$. Isoprene (Sigma Aldrich, 99\%) was purified over $\mathrm{CaH}_{2}$, distilled twice over $n-\mathrm{BuLi}$, and finally stored at $-20{ }^{\circ} \mathrm{C}$. sec-Butyllithium (1.4 M in cyclohexane, Sigma-Aldrich) was diluted to the appropriate concentration in purified benzene in a specific glass apparatus under a high vacuum. EO (Sigma-Aldrich, 99.5\%) was purified by successive distillations over $\mathrm{CaH}_{2}$ and $n$-BuLi at $0{ }^{\circ} \mathrm{C}$ and finally stored under high vacuum. Methanol was purified by successive distillations over $\mathrm{CaH}_{2}$ and stored under a high vacuum. All the above purification methods were performed in custom-made glass apparatuses by employing high-vacuum techniques and standard procedures, based on the requirements of anionic polymerization, described in detail elsewhere. ${ }^{53,54}$

For Ring-Opening Polymerization. Methanol ( $\mathrm{MeOH})$, tetrahydrofuran (THF), dichloromethane (DCM), ethyl acetate (EtOAc), and diethyl ether $\left(\mathrm{Et}_{2} \mathrm{O}\right)$ were purchased from VWR Chemicals (HiPerSolv CHROMANORM). 1,4-Dioxane (anhydrous, >99.9\%), benzoic acid (99.5\%), and toluene were dried by distillation over calcium hydride $\left(\mathrm{CaH}_{2}, 95 \%\right)$ and polystyrilithium. THF was purified by distillation over $\mathrm{CaH}_{2}$ and sodium/benzophenone. Phenyl propanol (PPA; 99.8\%, Sigma-Aldrich) was distilled two times over $\mathrm{CaH}_{2}$ under vacuum. LLA (Alfa-Aesar, 99\%) and DLA (Jinan Daigang Biomaterial Co., Ltd, $\geq 99.5 \%$ ) were recrystallized from EtOAc three times, cryo-evaporation from 1,4-dioxane, followed by drying under vacuum overnight. $\mathrm{Sn}(\mathrm{Oct})_{2},(95 \%$, Sigma-Aldrich) was distilled twice over anhydrous $\mathrm{MgSO}_{4}$ and activated $4 \AA$ molecular sieves followed by azeotropic distillation with dry toluene. All monomers, solvents, and catalysts were stored under argon $(\mathrm{Ar})$ in a glovebox (LABmaster ${ }^{\text {pro }}$ SP, MBraun, Germany). 
Scheme 1. Procedures to Synthesize PS-OH and PI-OH Macroinitiators by Anionic Polymerization and the Subsequent ROP of $\mathrm{D} / \mathrm{L}-\mathrm{LA}$ Catalyzed by $\mathrm{Sn}(\mathrm{Oct})_{2}$

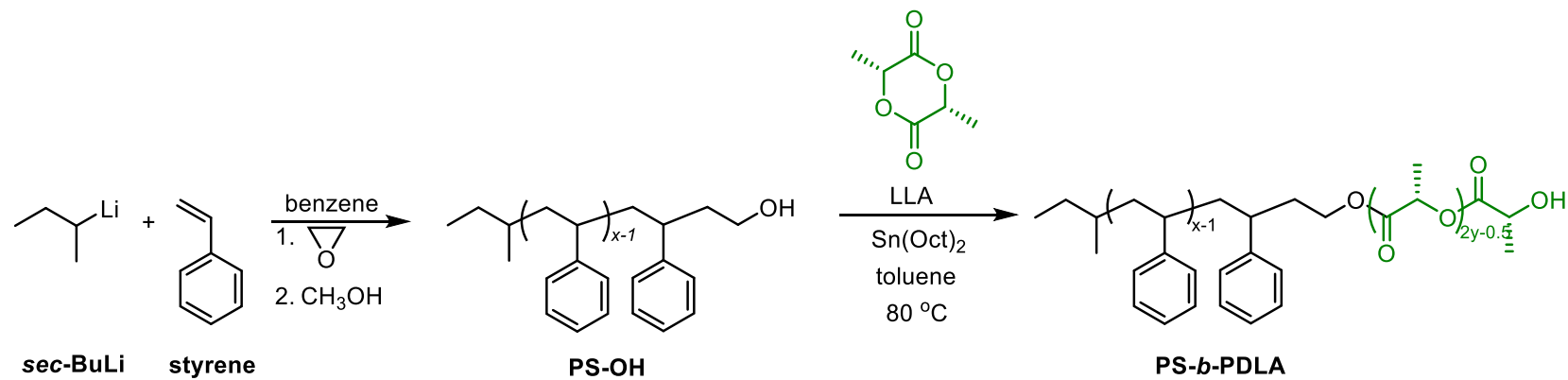

sec-BuLi styrene

after precipitation and drying

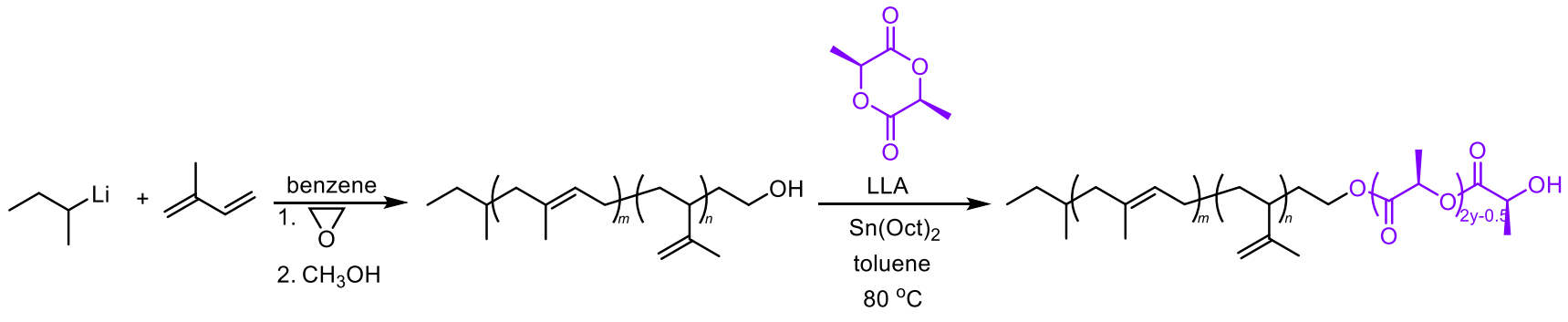

sec-BuLi isoprene

$\mathrm{PI}-\mathrm{OH}$

PS-b-PLLA

after precipitation and drying

Instrumentation. NMR measurements were performed at room temperature using Bruker AVANCEDIII spectrometers operating at 400 and $950 \mathrm{MHz} ; \mathrm{CDCl}_{3}$ was used as the solvent. ${ }^{1} \mathrm{H}$ NMR spectra were used to determine the number average molecular weight $\left(M_{\mathrm{n}, \mathrm{NMR}}\right)$ of the polymer by calculating the integral ratio of the protons end group and the characteristics of protons on the main chain. GPC measurements were performed in an Agilent GPC instrument (Agilent Technologies) equipped with a PLgel $5 \mu \mathrm{m}$ MIXED-C and PLgel $5 \mu \mathrm{m}$ MIXED-D columns. THF was used as the eluent at a flow rate of $1.0 \mathrm{~mL} \mathrm{~min}{ }^{-1}$ at $35{ }^{\circ} \mathrm{C}$. The instrument was calibrated with PS standards. DSC measurements were performed with a Mettler Toledo DSC1/TC100 under nitrogen and calibrated with indium. The samples were first heated from $-80{ }^{\circ} \mathrm{C}$ (for PIbased blocks) or from $-20^{\circ} \mathrm{C}$ (for PS-based blocks) to $200^{\circ} \mathrm{C}$, then cooled again, and finally heated again to $200{ }^{\circ} \mathrm{C}$ at a heating/cooling rate of $10{ }^{\circ} \mathrm{C} \mathrm{min}^{-1}$. This cycle was repeated two times, and the glass transition temperature $\left(T_{\mathrm{g}}\right)$, melting, and cooling temperatures $\left(T_{\mathrm{m}}\right.$ and $T_{c}$ ) were recorded. XRD spectra were obtained using a XRD Bruker D8 ADVANCE with $\mathrm{Cu} \mathrm{K} \alpha$ radiation. The samples for XRD measurements were deposited on a glass substrate (from $\mathrm{CHCl}_{3}$ solution) with an approximate size of $1.5 \mathrm{~cm} \times 1 \mathrm{~cm}$, pre-annealed at $170-180{ }^{\circ} \mathrm{C}$ for $10 \mathrm{~min}$, and cooled down to room temperature with a cooling rate of $10{ }^{\circ} \mathrm{C} \mathrm{min}^{-1}$.

The PS- $b$-PDLA and PI- $b$-PLLA thin films were prepared from chloroform solution $\left(10 \mathrm{mg} \mathrm{mL} \mathrm{m}^{-1}\right)$, while the $\mathrm{SC}$ thin film was prepared from toluene solution. The silicon $(\mathrm{Si})$ substrates were treated with a mixture of $98 \% \mathrm{H}_{2} \mathrm{SO}_{4}$ and $30 \% \mathrm{H}_{2} \mathrm{O}_{2}$ (volume ratio $2: 1$ ). The polymer solutions were spin-coated on top of the $\mathrm{Si}$ substrates at $300 \mathrm{rpm}$ for $15 \mathrm{~s}$ and $2500 \mathrm{rpm}$ for $50 \mathrm{~s}$.

The surface topography information for all the samples was measured by adjusting the strength of the tapping mode-AFM. A Bruker Dimension Icon AFM (scanning probe microscope) was used under air at room temperature. The measurements were performed using phosphorus-doped Si tips (TAP150A) of resonance frequency ranging between 120 and $162 \mathrm{~Hz}$, with a force constant $(k)$ of $5 \mathrm{~N}$ $\mathrm{m}^{-1}$. Image analysis software (IA 3.5) was applied for the analysis of height images and the corresponding cross-sectional line profiles.

Synthetic Procedure. Synthesis of PS-OH. All synthetic procedures were performed using conventional high-vacuum techniques. The anionic polymerization was carried out in evacuated, $n$-BuLi washed custom-made glass reactors. Reagents were added via break-seals, and aliquots for characterization were taken at all steps. More details concerning the techniques and the apparatuses used are given in previous reports. ${ }^{52-54}$ As an example, the synthesis of PS-OH $5500 \mathrm{~g} \mathrm{~mol}^{-1}$ is given below.

Styrene $(5 \mathrm{~g})$ was added to $100 \mathrm{~mL}$ of benzene, followed by the addition of sec-BuLi ( $1 \mathrm{mmol})$, and kept for $18 \mathrm{~h}$ at room temperature. After completion of polymerization, an aliquot was taken to verify the molecular characteristics of the synthesized PS. Subsequently, EO $(\sim 1 \mathrm{~mL})$ was added to the reaction mixture and left for $12 \mathrm{~h}$ at room temperature, and the reaction was terminated by the addition of methanol $(\sim 0.5 \mathrm{~mL})$ (Scheme 1$)$. The polymerization solution was precipitated into an excess of methanol, and the polymer was dried in a vacuum oven for $24 \mathrm{~h}$ at $40{ }^{\circ} \mathrm{C}$. The number-average molecular weight $\left(M_{n}\right)$ and dispersity index $(D)$ of PS-OH were calculated by GPC $\left(M_{\mathrm{n}}=5500 \mathrm{~g} \mathrm{~mol}^{-1}\right.$ and $\left.B=1.05\right)$ calibrated with PS standards. ${ }^{1} \mathrm{H}$ NMR PS-OH $\left(400 \mathrm{MHz}, \mathrm{CDCl}_{3}, 25^{\circ} \mathrm{C}\right): \delta \mathrm{ppm}$ 0.41-0.67 (8H; sec-Bu), 0.69-1.55 (2H; $\left.-\mathrm{CH}_{2}-\mathrm{CH}-\mathrm{Ph}\right), 1.56-$ $2.15\left(1 \mathrm{H} ; \mathrm{CH}_{2}-\mathrm{CH}(\mathrm{Ph})-\mathrm{CH}_{2}\right), 3.06-3.33\left(2 \mathrm{H} ;-\mathrm{CH}_{2}-\mathrm{OH}\right)$, 6.28-7.25 (phenyl protons).

Synthesis of PS- $b-P D L A$. A dry polymerization flask equipped with a stirrer bar was charged with $440 \mathrm{mg}$ of dry PS-OH $5500 \mathrm{~g} \mathrm{~mol}^{-1}$ $(0.08 \mathrm{mmol}), 16.2 \mathrm{mg}$ of $\mathrm{Sn}(\mathrm{Oct})_{2}(0.04 \mathrm{mmol}), 403 \mathrm{mg}$ of D-LA $(2.8$ $\mathrm{mmol}$ ), and $7 \mathrm{~mL}$ of dry toluene under an $\mathrm{Ar}$ atmosphere. The flask was sealed and placed in an oil bath at $80{ }^{\circ} \mathrm{C}$. After $24 \mathrm{~h}$, the conversion of D-LA reached $96.0 \%$. The ROP was quenched with benzoic acid, and the solution was precipitated in cold $\mathrm{MeOH}\left(0{ }^{\circ} \mathrm{C}\right)$. PS- $b$-PDLA was isolated by centrifugation and dried in vacuo for $24 \mathrm{~h}$ at $40{ }^{\circ} \mathrm{C} .{ }^{1} \mathrm{H}$ NMR PS- $b$-PDLA $\left(400 \mathrm{MHz}, \mathrm{CDCl}_{3}, 25{ }^{\circ} \mathrm{C}\right): \delta \mathrm{ppm}$ $0.41-0.67(8 \mathrm{H} ; \mathrm{sec}-\mathrm{Bu}), 0.69-1.55\left(2 \mathrm{H} ;-\mathrm{CH}_{2}-\mathrm{CH}(\mathrm{Ph}), 1.52-1.66\right.$ (d, $\left.3 \mathrm{H} ;-\mathrm{CH}\left(\mathrm{CH}_{3}\right)-\mathrm{COO}\right), 1.56-2.15\left(1 \mathrm{H} ; \mathrm{CH}_{2}-\mathrm{CH}(\mathrm{Ph})-\mathrm{CH}_{2}\right)$, 3.66-3.89 (2H; $\left.\mathrm{CH}_{2}-\mathrm{CH}_{2}-\mathrm{OCO}\right), 4.32-4.41\left(1 \mathrm{H} ;-\mathrm{CH}\left(\mathrm{CH}_{3}\right)-\right.$ $\mathrm{COO}$ end-group), 5.05-5.31 (1H; $\left.-\mathrm{CH}\left(\mathrm{CH}_{3}\right)-\mathrm{COO}\right), 6.28-7.25$ (phenyl protons).

Synthesis of $\mathrm{PI}-\mathrm{OH}$. A similar procedure as above was followed for the synthesis of $\omega-\mathrm{OH}$ functionalized polyisoprene samples. A typical example is as follows. Isoprene $(9.86 \mathrm{~g})$ was added to $120 \mathrm{~mL}$ of benzene, followed by the addition of sec-BuLi $(1.812 \mathrm{mmol})$, and kept 
for $24 \mathrm{~h}$ at room temperature. After completion of polymerization, an aliquot was taken for molecular characterization. Subsequently, EO $(\sim 1 \mathrm{~mL})$ was added to the reaction mixture, and after $12 \mathrm{~h}$, the reaction was terminated by the addition of methanol $(\sim 0.5 \mathrm{~mL})$ (Scheme 1). The polymerization solution was precipitated into an excess of methanol, and the polymer was dried in a vacuum oven overnight at $40{ }^{\circ} \mathrm{C} . M_{\mathrm{n}}$ of PI-OH was calculated by ${ }^{1} \mathrm{H} \mathrm{NMR}\left(M_{\mathrm{n}}=\right.$ $6000 \mathrm{~g} \mathrm{~mol}^{-1}$ ), while $\mathrm{B}(1.03)$ was obtained from GPC. The anionic polymerization of isoprene in benzene at room temperature led to polyisoprene with high 1,4-microstructure $(90-92 \%)$ in all cases, as indicated by the ${ }^{1} \mathrm{H}$ NMR analysis. ${ }^{1} \mathrm{H}$ NMR PI-OH $(950 \mathrm{MHz}$, $\left.\mathrm{CDCl}_{3}, 25^{\circ} \mathrm{C}\right): \delta$ ppm 1.44-1.54 $\left(3 \mathrm{H} ;-\mathrm{CH}_{3}, 3,4\right.$-microstructure), $1.55-1,63\left(3 \mathrm{H} ;-\mathrm{CH}_{3}, 1,4\right.$-microstructure $), 1.83-2.02(2 \mathrm{H}$; $\left.-\mathrm{CH}_{2}-\right), 3.41-3.61\left(2 \mathrm{H} ;-\mathrm{CH}_{2}-\mathrm{OH}\right), 4.49-4.71(2 \mathrm{H} ; 3,4-$ microstructure), $4.90-5.08(1 \mathrm{H} ; 1,4$-microstructure $)$.

Synthesis of PI-b-PLLA. A dry polymerization flask equipped with a stirrer bar was charged with $480 \mathrm{mg}$ of dry PI-OH $6000 \mathrm{~g} \mathrm{~mol}^{-1}(0.08$ $\mathrm{mmol}), 16.2 \mathrm{mg}$ of $\mathrm{Sn}(\mathrm{Oct})_{2}(0.04 \mathrm{mmol}), 403 \mathrm{mg}$ of L-LA $(2.8$ $\mathrm{mmol}$ ), and $7 \mathrm{~mL}$ of dry toluene under an $\mathrm{Ar}$ atmosphere. The flask was sealed and placed in an oil bath at $80{ }^{\circ} \mathrm{C}$. After $24 \mathrm{~h}$, the conversion of LLA reached $96.0 \%$, and then, the whole reaction mixture was quenched with benzoic acid and precipitated in cold $\mathrm{MeOH}$. PI- $b$-PLLA was isolated by centrifugation and dried in vacuo for $24 \mathrm{~h}$ at $40{ }^{\circ} \mathrm{C} .{ }^{1} \mathrm{H}$ NMR PI- $b$-PLLA $\left(950 \mathrm{MHz}, \mathrm{CDCl}_{3}, 25{ }^{\circ} \mathrm{C}\right): \delta$ ppm 1.44-1.54 (3H; $-\mathrm{CH}_{3}, 3,4$-microstructure), $1.55-1.66(\mathrm{~d}, 3 \mathrm{H}$; $\left.-\mathrm{CH}\left(\mathrm{CH}_{3}\right)-\mathrm{COO}\right), \quad 1.55-1,63\left(3 \mathrm{H} ;-\mathrm{CH}_{2}, 3 \mathrm{H} ;-\mathrm{CH}_{3}, 1,4-\right.$ microstructure), $1.83-2.02\left(2 \mathrm{H} ;-\mathrm{CH}_{2}-\right), 3.97-4.14\left(2 \mathrm{H} ; \mathrm{CH}_{2}-\right.$ $\left.\mathrm{CH}_{2}-\mathrm{OCO}\right), 4.33-4.31\left(1 \mathrm{H} ;-\mathrm{CH}\left(\mathrm{CH}_{3}\right)-\mathrm{COO}\right.$ end-group), 4.49$4.71(2 \mathrm{H} ; 3,4$-microstructure $), 4.90-5.08(1 \mathrm{H} ; 1,4$-microstructure $)$, $5.15-5.23\left(1 \mathrm{H} ;-\mathrm{CH}\left(\mathrm{CH}_{3}\right)-\mathrm{COO}\right)$.

Procedures for the Preparation of PS-SC-PI by Stereocomplexation. Equimolar solutions of PS-b-PDLA and PI- $b$-PLLA were dissolved in DCM separately and stirred for $15 \mathrm{~min}$. Both solutions were mixed for $10 \mathrm{~min}$, and then the whole solution was poured to $300 \mathrm{~mL}$ of cold methanol in a $500 \mathrm{~mL}$ beaker equipped with a stirrer bar. Stirring was continued for $30 \mathrm{~min}$ at $200 \mathrm{rpm}$. The precipitates were recovered by centrifugation, decantation, and dried in vacuo at $40{ }^{\circ} \mathrm{C}$ for $48 \mathrm{~h} .{ }^{1} \mathrm{H}$ NMR PI-SC-PLLA $(950 \mathrm{MHz}$, $\left.\mathrm{CDCl}_{3}, 25{ }^{\circ} \mathrm{C}\right): \delta$ ppm $0.41-0.67(8 \mathrm{H} ;$ sec-Bu $), 0.69-1.55(2 \mathrm{H}$; $-\mathrm{CH}_{2}-\mathrm{CH}(\mathrm{Ph}), 1.44-1.54\left(3 \mathrm{H} ;-\mathrm{CH}_{3}, 3,4\right.$-microstructure $), 1.55-$ $1.66\left(\mathrm{~d}, 3 \mathrm{H} ;-\mathrm{CH}\left(\mathrm{CH}_{3}\right)-\mathrm{COO}\right), 1.55-1.63\left(3 \mathrm{H} ;-\mathrm{CH}_{2}, 3 \mathrm{H} ;-\mathrm{CH}_{3}\right.$, 1,4-microstructure), $1.56-2.15\left(1 \mathrm{H} ; \mathrm{CH}_{2}-\mathrm{CH}(\mathrm{Ph})-\mathrm{CH}_{2}\right), 1.70-$ $2.13\left(\mathrm{H} ;-\mathrm{CH}_{2}-\right), 3.66-3.89\left(2 \mathrm{H} ; \mathrm{CH}_{2}-\mathrm{CH}_{2}-\mathrm{OCO}\right), 3.97-4.14$ $\left(2 \mathrm{H} ; \mathrm{CH}_{2}-\mathrm{CH}_{2}-\mathrm{OCO}\right), 4.32-4.41\left(1 \mathrm{H} ;-\mathrm{CH}\left(\mathrm{CH}_{3}\right)-\mathrm{COO}\right.$ endgroup), 4.62-4.81 (2H; 3,4-microstructure), 5.04-5.14 $(1 \mathrm{H} ; 1,4-$ microstructure $), 5.15-5.25\left(1 \mathrm{H} ;-\mathrm{CH}\left(\mathrm{CH}_{3}\right)-\mathrm{COO}\right), 6.28-7.25$ (phenyl protons).

\section{RESULTS AND DISCUSSION}

The anionic polymerizations of isoprene and styrene were carried out in benzene at room temperature using secbutyllithium as the initiator (Scheme 1). After the complete conversion of the monomers, the living PS and PI chains were end-capped by addition of excess $\mathrm{EO}$ at room temperature. Only one EO monomeric unit reacts with the living carbanion, resulting in PS and PI with a $-\mathrm{CH}_{2}-\mathrm{CH}_{2}-\mathrm{O}^{-} \mathrm{Li}^{+}$terminal. The $\omega$-hydroxyl functionalized PS and PI were obtained by termination of the alkoxy anion with methanol. In general, the end-capping of the living chain end with EO followed by the addition of methanol results in $\mathrm{OH}$-functionalized polymers with a high degree of functionalization $(>99 \%) .{ }^{55,56}$

$\mathrm{PS}-\mathrm{OH}$ and PI-OH macroinitiators with three different targeted molecular weights: 5,10 , and $20 \mathrm{~kg} \mathrm{~mol}^{-1}$ were prepared. Their molecular characteristics are presented in Table S1 of the Supporting Information. All polymers exhibit narrow polydispersity $(<1.07)$, indicating that the polymers are well-defined. It was expected that anionic polymerization of isoprene using $s e c-\mathrm{BuLi}$ as the initiator and benzene as the solvent would lead to the formation of PI having a high content of cis-1,4 microstructure, which will be discussed later in the NMR section. ${ }^{57}$

Dry PI-OH and PS-OH were used as the macroinitiators to initiate the ROP of D/L-LA using $\mathrm{Sn}(\mathrm{Oct})_{2}$ as a catalyst in toluene at $80{ }^{\circ} \mathrm{C}$ (Scheme 1). The reaction conditions and the results of the molecular characterization are presented in Table 1. $\mathrm{Sn}(\mathrm{Oct})_{2}$ was chosen as the catalyst for the ROP of LA at 80

Table 1. Molecular Characteristics of Diblock Copolymers Prepared by ROP of D/L-LA with PS-OH/PI-OH Macroinitiators $^{a}$

\begin{tabular}{|c|c|c|c|c|c|}
\hline entry & sample & $\underset{(\mathrm{h})}{\mathrm{time}}$ & $\begin{array}{c}\text { conv. }^{b} \\
(\%)\end{array}$ & $\begin{array}{l}M_{\text {n LA,NMR }}{ }^{c} \\
\left(\mathrm{~kg} \mathrm{~mol}^{-1}\right)\end{array}$ & $B_{\mathrm{M}}{ }^{d}$ \\
\hline 1 & $\mathrm{PS}_{18}-b-\mathrm{PDLA}_{10}$ & 16 & 100 & 10.1 & 1.08 \\
\hline 2 & $\mathrm{PI}_{22}-b-\mathrm{PLLA}_{10}$ & 16 & 99 & 9.9 & 1.07 \\
\hline 3 & $\mathrm{PS}_{18^{-}} b-\mathrm{PDLA}_{3.6}$ & 26 & 100 & 3.6 & 1.02 \\
\hline 4 & $\mathrm{PI}_{22}-b-\mathrm{PLLA}_{3.6}$ & 26 & 98 & 3.5 & 1.04 \\
\hline 5 & $\mathrm{PS}_{11}-b-\mathrm{PDLA}_{7}$ & 24 & 98 & 6.8 & 1.02 \\
\hline 6 & $\mathrm{PI}_{12}-b-\mathrm{PLLA}_{7}$ & 24 & 97 & 6.9 & 1.03 \\
\hline 7 & $\mathrm{PS}_{11}-b-\mathrm{PDLA}_{5}$ & 36 & 98 & 5.1 & 1.02 \\
\hline 8 & $\mathrm{PI}_{12}-b-\mathrm{PLLA}_{5}$ & 36 & 97 & 4.8 & 1.06 \\
\hline 9 & $\mathrm{PS}_{5.5^{-}-\mathrm{PDLA}_{5}}$ & 26 & 99 & 5.0 & 1.04 \\
\hline 10 & $\mathrm{PI}_{6}-b-\mathrm{PLLA}_{5}$ & 26 & 98 & 4.9 & 1.05 \\
\hline 11 & $\mathrm{PS}_{5.5}-b-\mathrm{PDLA}_{3.6}$ & 24 & 97 & 3.5 & 1.06 \\
\hline 12 & $\mathrm{PI}_{6}-b-\mathrm{PLLA}_{3.6}$ & 24 & 98 & 3.7 & 1.03 \\
\hline 13 & $\mathrm{PS}_{5.5}-b-\mathrm{PDLA}_{7}$ & 24 & 99 & 7.2 & 1.02 \\
\hline 14 & $\mathrm{PI}_{6}-b-\mathrm{PLLA}_{7}$ & 24 & 99 & 7.1 & 1.04 \\
\hline
\end{tabular}

${ }^{a_{T}}$ The PI-OH and PS-OH macroinitiators were prepared by the anionic polymerization high-vacuum technique. The ROP of D/L-LA was performed using $\mathrm{Sn}(\mathrm{Oct})_{2}$ as the catalyst in toluene at $80{ }^{\circ} \mathrm{C}$. ${ }^{b}$ Conversions of $\mathrm{D} / \mathrm{L}-\mathrm{LA}$ determined by analyzing the ${ }^{1} \mathrm{H}$ NMR spectra of crude products in $\mathrm{CDCl}_{3}$ at $25{ }^{\circ} \mathrm{C}$. ${ }^{c}$ Determined by analyzing the $400 \mathrm{MHz}{ }^{1} \mathrm{H}$ NMR spectra of the isolated polymers in $\mathrm{CDCl}_{3}$ at $25{ }^{\circ} \mathrm{C}$. ${ }^{d}$ Determined by SEC in THF at $35{ }^{\circ} \mathrm{C}$ (PS standards).

${ }^{\circ} \mathrm{C}$ or above because in this condition, LA undergoes a minimum racemization side reaction, resulting in PLAs with high isotactic content. ${ }^{58}$ Two PLLA homopolymers with molecular weights of 7000 and $3500 \mathrm{~g} \mathrm{~mol}^{-1}$ were also synthesized under the same conditions using phenyl propanol as the initiator to compare their physical properties with the corresponding PLAs in the block copolymers.

Figure 1 shows the ${ }^{1} \mathrm{H}$ NMR spectra of the representative homopolymer precursors $\left(\mathrm{PS}_{5.5}-\mathrm{OH}\right.$ and $\left.\mathrm{PI}_{6}-\mathrm{OH}\right)$, block copolymers $\left(\mathrm{PS}_{5.5}-b-\mathrm{PDLA}_{5}\right.$ and $\left.\mathrm{PI}_{6}-b-\mathrm{PLLA}_{5}\right)$, and $\mathrm{PS}_{5.5}-$ $\mathrm{SC}_{5}-\mathrm{PI}_{6}$. Calculation from the integral ratio of $\mathrm{b}$ and $\mathrm{c}$ reveals that the PI has $90 \% 1,4$ isomers and 10\% 3,4 isomers. The $\mathrm{CH}_{2}-\mathrm{OH}$ protons of the $\omega$-functionalized PS and PI appear at 3.22 (a) and $3.50 \mathrm{ppm}$ (d), respectively. $M_{\mathrm{n}}$ of PS-OH is determined from the integral ratio of a with the aromatic protons, whereas the $M_{\mathrm{n}}$ of PI is determined from the integral ratio of $d$ with $b+c$. After the ROP of D/L-LA, protons a and $d$ shifted downfield to 3.81 and $4.04 \mathrm{ppm}$, indicating that initiation of $\mathrm{D} / \mathrm{L}-\mathrm{LA}$ occurs from the terminal hydroxyl group of PS and PI. PS and PI are covalently linked to $\mathrm{PD} / \mathrm{L}-\mathrm{LA}$ as the second block through the formation of an ester bond from the oxygen atom at the $\omega$-end. The methine protons of the PLA end-group $(\mathrm{g})$ for both PS- $b$-PDLA and PI- $b$-PLLA diblock copolymers are observed at the same chemical shift (4.35 $\mathrm{ppm})$. The integral ratio between this proton $(\mathrm{g})$ with the 


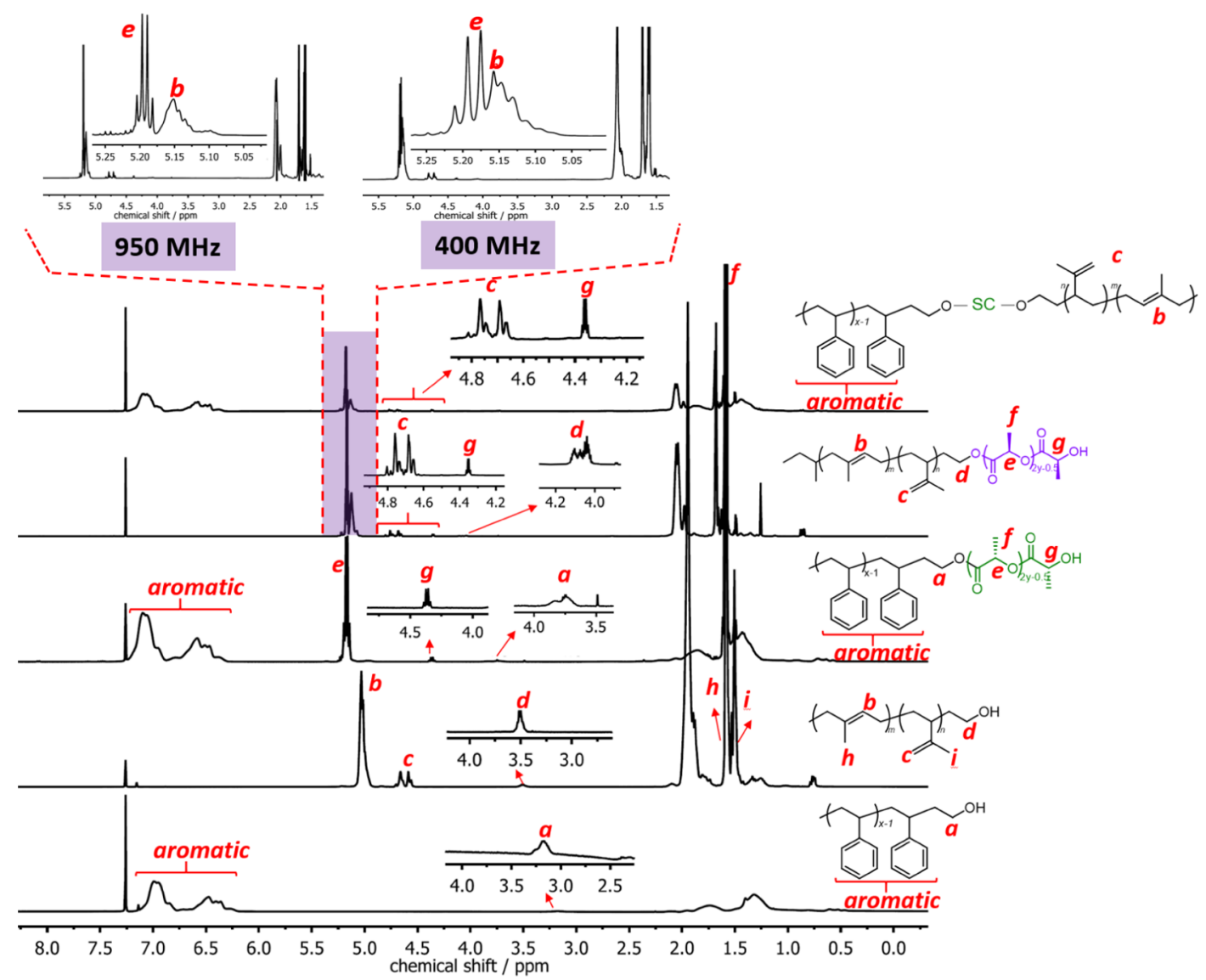

Figure 1. Representative ${ }^{1} \mathrm{H}$ NMR spectra of homopolymers precursors $\left(\mathrm{PS}_{5.5}-\mathrm{OH}\right.$ and $\left.\mathrm{PI}_{6}-\mathrm{OH}\right)$, block copolymers $\left(\mathrm{PS}_{5.5}-b-\mathrm{PDLA}_{5}\right.$ and $\mathrm{PI}_{6}-b$ $\mathrm{PLLA}_{5}$ ), and SC PS $5.5-\mathrm{SC}_{5}-b-\mathrm{PI}_{6}$. The spectra were recorded with a $400 \mathrm{MHz}$ spectrometer except for $\mathrm{PI}_{6}-b-\mathrm{PLLA}_{5}$ and $\mathrm{PS}_{5.5}-b-\mathrm{SC}_{5}-b-\mathrm{PI}_{6}[$ the spectra were recorded with a $950 \mathrm{MHz}$ spectrometer $\left.\left(\mathrm{CDCl}_{3}, 25^{\circ} \mathrm{C}\right)\right]$.
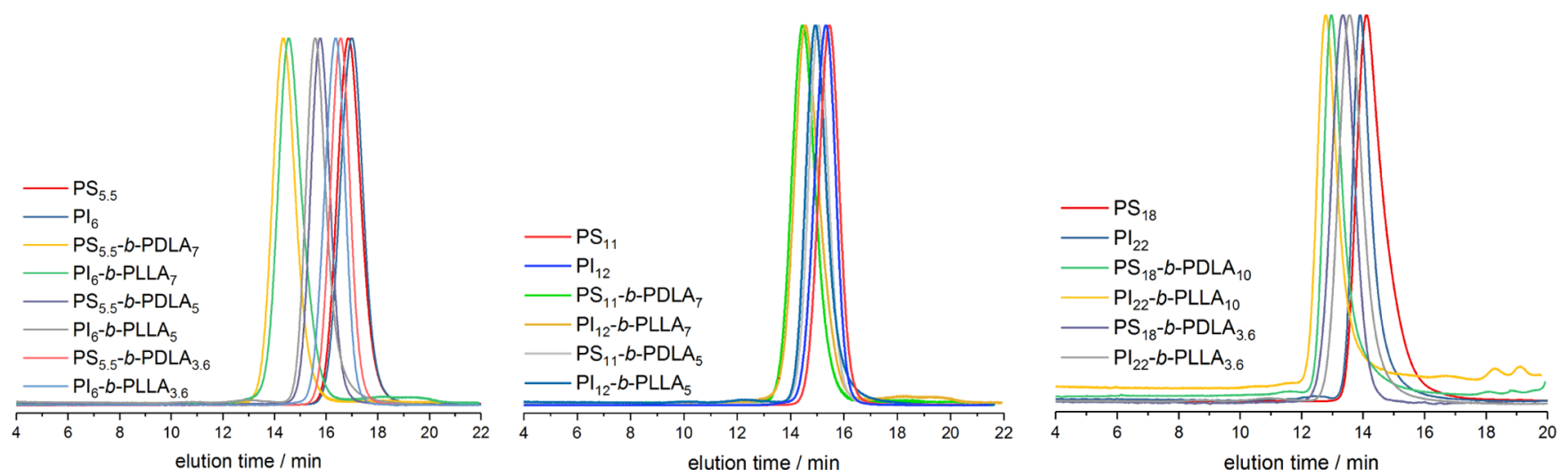

Figure 2. GPC traces of the precursors (PS and PI) and the corresponding diblock copolymers with PLAs (THF, $35^{\circ} \mathrm{C}$, PS standards).

methine proton from the main chain PLA (e) is used to determine the $M_{\mathrm{n}}$ of the PLA blocks.

It is worth noting that the methylene protons of PI (b) and the methine proton of PLLA (e) are observed as overlapped peaks on the $400 \mathrm{MHz}{ }^{1} \mathrm{H}$ NMR spectrometer. Hillmyer et al. reported that $M_{\mathrm{n}}$ of PI- $b$-PLLA and the mass fraction of PLLA in the diblock were calculated indirectly by combining ${ }^{1} \mathrm{H}$ and ${ }^{13} \mathrm{C}$ NMR spectroscopy and comparing the result with elemental analysis. However, in our work, we used a 950 $\mathrm{MHz}{ }^{1} \mathrm{H}$ spectrometer to resolve peaks (b) and (e) into a wellseparated peak (Figure 1). Thus, the $M_{n}$ of PLLA can be determined directly by quantitative end-group analysis from the integral ratio of peak $(\mathrm{g})$ with peak (e) of the PLA main chain.

The molecular weight distributions $(D)$ of the PS-OH and PI-OH homopolymers as well as the PS- $b$-PDLA and PI- $b$ PLLA diblock copolymers, were determined by GPC with THF as the eluent. Figures 2 and S1 show the narrow molecular weight distribution of the homo- and diblock copolymers ( $D$ is usually $<1.10$ ), verifying the absolute control of the anionic polymerization and ROP systems used in this work. The GPC traces of the diblock copolymers in Figure 2 appeared in the lower elution time, indicate the increase of molecular weight compared to the macroinitiators and thus 
support the formation of a diblock copolymer. All GPC traces of the diblock copolymers are monomodal, and no indication of residue from their precursors was detected. The small shoulder between 18 and 20 min (outside of the calibration range) on the GPC trace of $\mathrm{PI}_{22}-b$-PLLA 10 is attributed to $3,5-$ di-tert-4-butylhydroxytoluene, the radical inhibitor used to stabilize THF. The purity of the diblock copolymers is also corroborated by 2D-diffusion-ordered spectroscopy (DOSY) spectra of $\mathrm{PS}_{11}-b$-PDLA 7 and $\mathrm{PI}_{12}-b-\mathrm{PLLA}_{7}$ (as the representative samples, Figure S2) which show that only one macromolecule exists in each sample.

The formation of diblock copolymers and the corresponding SC was further investigated by FT-IR spectroscopy. Figure 3

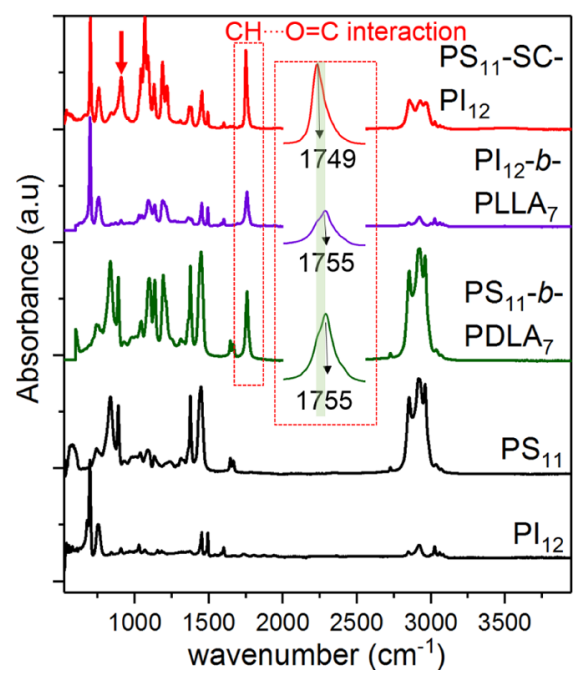

Figure 3. FT-IR spectra of the representative polymers indicating the shift of the wavenumber of the carbonyl carbon after the formation of SC.

shows the FT-IR spectra of the homopolymers $\left(\mathrm{PS}_{11}-\mathrm{OH}\right.$ and $\left.\mathrm{PI}_{12}-\mathrm{OH}\right)$, block copolymers $\left(\mathrm{PS}_{11}-b-\mathrm{PDLA}_{7}\right.$ and $\mathrm{PI}_{12}-b$ $\mathrm{PLLA}_{7}$ ), and $\mathrm{PS}_{11}-\mathrm{SC}_{7}-\mathrm{PI}_{12}$ as the representative samples. We focused on the vibrational stretch of the carbonyl group of polylactide $(\nu(\mathrm{C}=\mathrm{O})$ band $)$ of the PS-PDLA and PI-PLLA diblock copolymers $\left(1755 \mathrm{~cm}^{-1}\right)$. Upon the formation of SC, the $\nu(\mathrm{C}=\mathrm{O})$ band shifts to a lower wavenumber (from 1755 to $\left.1749 \mathrm{~cm}^{-1}\right)$ (Figure 3). This shift $\left(\sim 5 \mathrm{~cm}^{-1}\right)$ is in good agreement with the case of $\mathrm{SC}_{7}$ samples derived from $\mathrm{PD} / \mathrm{L}-$ $\mathrm{LA}_{7}$ homopolymers (from 1755 to $1750 \mathrm{~cm}^{-1}$, Figure S3) and was also observed in the literature. ${ }^{59}$ Such a shift is due to the transition of the PLA chains from a disordered state to an ordered one via the $\mathrm{SC}$ formation by $\mathrm{CH}_{3} \cdots \mathrm{O}=\mathrm{C}$ intermolecular H-bond interaction. ${ }^{15,59}$ In addition, the SC formation is also supported by the appearance of the characteristic absorbance peak at $908 \mathrm{~cm}^{-1}$ (red arrow). ${ }^{60-62}$

$\mathrm{CD}$ experiments were carried out to evaluate the specific rotation of $\mathrm{PD} / \mathrm{L}-\mathrm{LA}$ of the homo and block copolymers and the change after stereocomplexation. Figure 4 shows the $\mathrm{CD}$ and UV absorption spectra of both $\mathrm{PS}_{11}-b$-PDLA 7 and $\mathrm{PI}_{12}-b$ $\mathrm{PLLA}_{7}$ in dilute ACN solution $\left(0.1 \mathrm{mg} \mathrm{mL}^{-1}\right)$. A positive Cotton effect of $\mathrm{PI}_{12}-b$-PLLA 7 (left-handed helicoidal conformation) and a negative Cotton effect of $\mathrm{PS}_{11}-b$-PDLA (right-handed helicoidal confirmation) were observed at $\sim 215 \mathrm{~nm}$, which is attributed to the characteristic absorption band of an $\mathrm{n} \rightarrow \pi^{*}$ transition of the carboxyl group. In contrast, the $\mathrm{PS}_{11}-\mathrm{SC}_{7}-\mathrm{PI}_{12}$ solution does not exhibit the

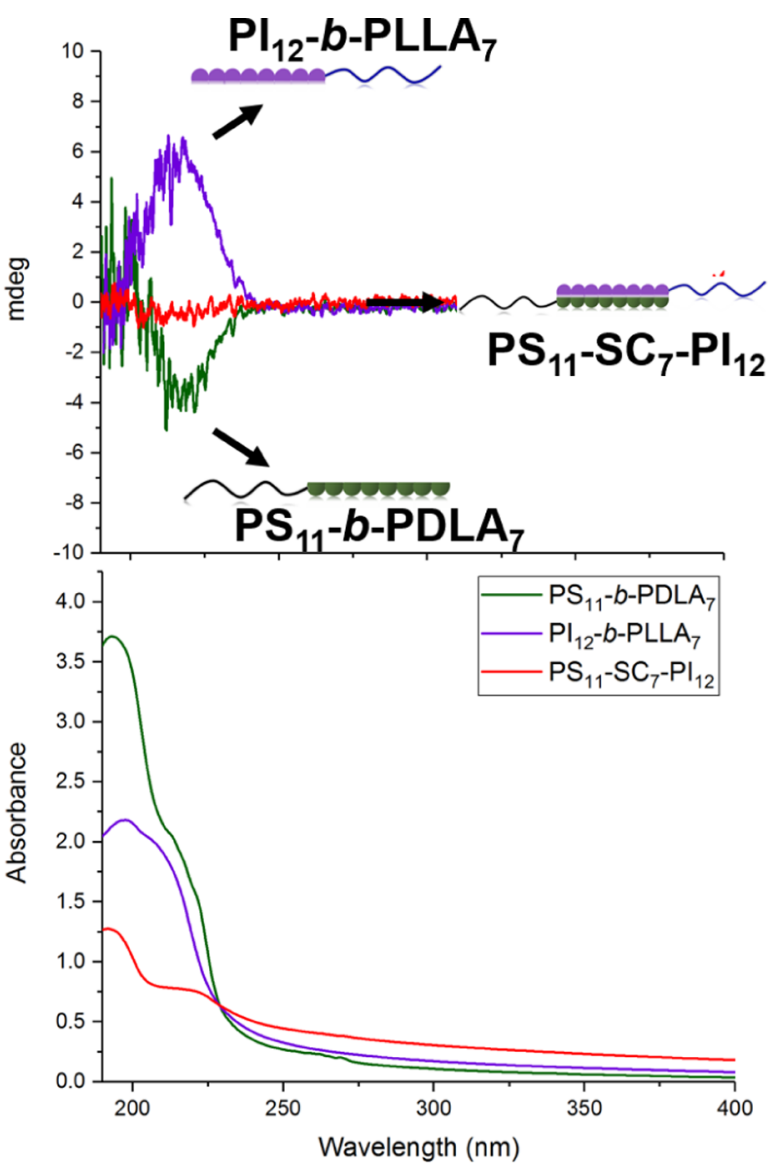

Figure 4. $\mathrm{CD}$ and UV spectra of $\mathrm{PS}_{11}-b-\mathrm{PDLA}_{7}, \mathrm{PI}_{12}-b-\mathrm{PLLA}_{7}$, and $\mathrm{PS}_{11}-\mathrm{SC}_{7}-\mathrm{PI}_{12}$ in acetonitrile at room temperature ([PDLA $]=0.047$ $\mathrm{mg} \mathrm{mL} L^{-1}$, [PLLA $]=0.055 \mathrm{mg} \mathrm{mL}^{-1}$ ).

Cotton effect (flat line, CD silence), indicating that a SC has been formed. Similar characteristics are also observed on the $\mathrm{PD} / \mathrm{L}-\mathrm{LA}_{7}$ and $\mathrm{SC}_{7}$ solution (Figure $\mathrm{S} 4$ ), indicating that the presence of PI and PS blocks does not hinder the formation of helicoidal conformation in diblock copolymers.

DSC was used to analyze the thermal properties of PS-OH and PI-OH macroinitiators, PS- $b$-PDLA and PI- $b$-PLLA diblock copolymers, as well as the SCs. The $T_{\mathrm{g}} \mathrm{s}$ were determined by finding the midpoint between the beginning and the end of transition temperatures. Figure S5 shows the thermograms of PS-OH and PI-OH macroinitiators, and the $T_{\mathrm{g}}$ values are summarized in Table S1. The $T_{\mathrm{g}} \mathrm{s}$ of PS-OH $\left(80^{\circ} \mathrm{C}\right.$ $\left.<T_{\text {g, PS-OH }}<98^{\circ} \mathrm{C}\right)$ and PI-OH $\left(-70{ }^{\circ} \mathrm{C}<T_{\text {g,PI-OH }}<-66{ }^{\circ} \mathrm{C}\right)$ increase with the increase of the molecular weight. Furthermore, all $T_{\mathrm{g}}$ values of PS-OH and PI-OH obtained in this work are in good agreement with the $T_{\mathrm{g}} \mathrm{s}$ from the previous reports, indicating the well-controlled anionic polymerization procedure. $^{63,64}$

We also performed a preliminary analysis of the thermal properties of the diblock copolymers. DSC traces of PI- $b$ PLLA block copolymers (Figure 5) show clear $T_{\mathrm{g}} \mathrm{s}$ of PI $\left(-63.5{ }^{\circ} \mathrm{C}<T_{\mathrm{g}, \mathrm{PI}}<-59{ }^{\circ} \mathrm{C}\right)$. Since the $T_{\mathrm{g}}$ of $\mathrm{PI}$ is much lower than the $T_{\mathrm{m}}$ of PLA, the mobility of the PI block is not significantly affected by the PLA crystal, although the chain is covalently linked to the PLA block. In contrast, for several PS$b$-PDLA samples, the $T_{\mathrm{g}} \mathrm{s}$ of PS are not observed probably because of the high melting enthalpy of the PLA or covered by 

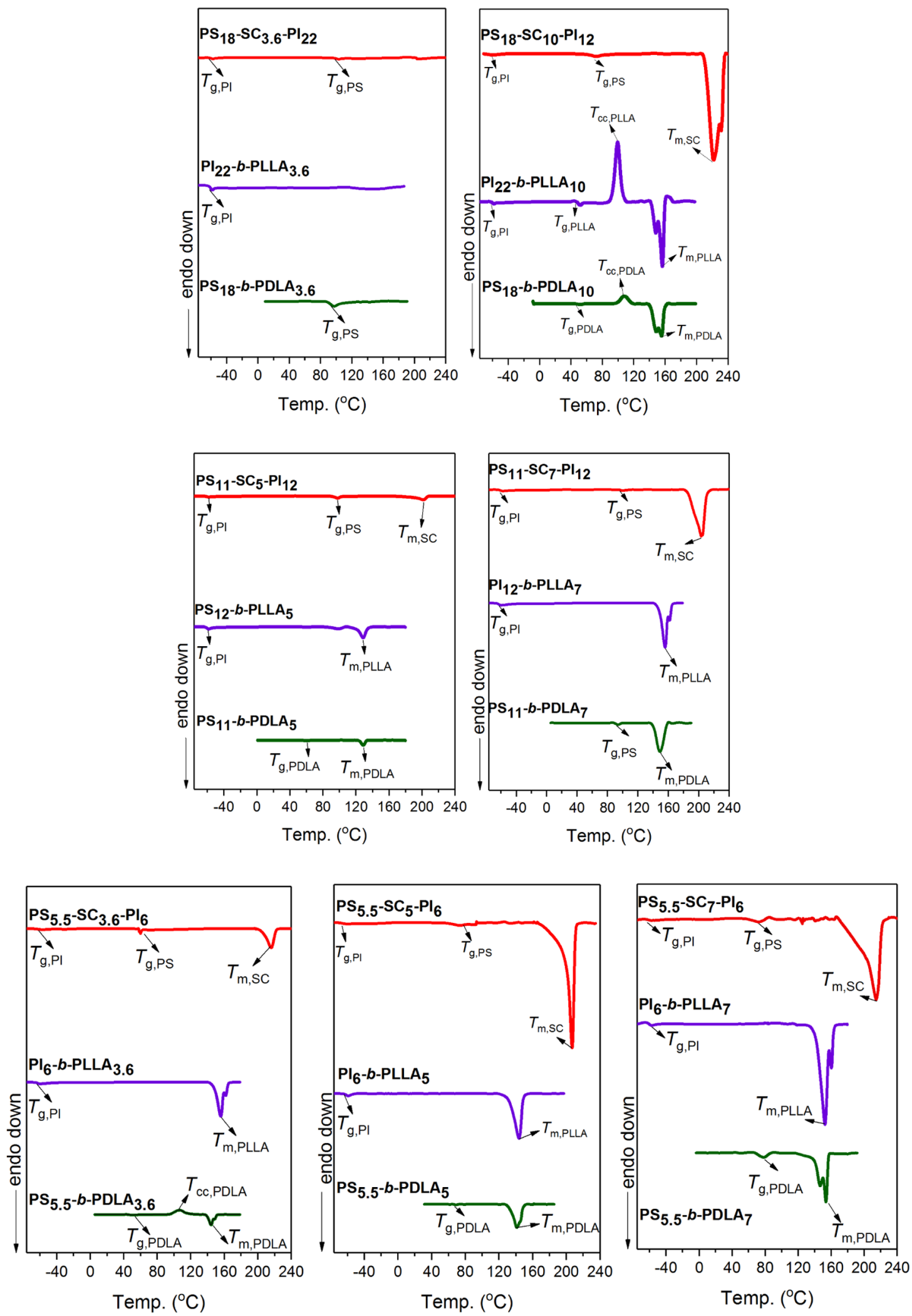

Figure 5. Endothermic DSC thermograms of diblock copolymers and the corresponding SC (the heating rate is $10^{\circ} \mathrm{C}$ min ${ }^{-1}$, under $\mathrm{N}_{2}$ ).

the $T_{\mathrm{cc}}$ of PDLA (for $\mathrm{PS}_{18}-b-\mathrm{PDLA}_{10}$ and $\mathrm{PS}_{5.5}-b-\mathrm{PDLA}_{3.6}$ samples). ${ }^{40,65}$

For both homo- and diblock copolymers, the $T_{\mathrm{m}} \mathrm{s}$ of PLAs are affected significantly by the molecular weight of the PLAs (Tables 2, S2, and Figure S6); the higher the molecular weights, the higher the $T_{\mathrm{m}} \mathrm{s}$ of PLAs of the polymers. In addition to the block copolymers, the $T_{\mathrm{m}}$ of PLAs is also influenced by the molecular weight of the amorphous block. For most diblock copolymers $\left(\mathrm{PLA}_{3.5}\right.$ and $\left.\mathrm{PLA}_{7}\right)$, the $T_{\mathrm{m}} \mathrm{s}$ of the PLA block are lower than the $T_{\mathrm{m}} \mathrm{s}$ of PLA homopolymers 
Table 2. Thermal and Physical Properties of Diblock Copolymers and Their Corresponding SC

\begin{tabular}{|c|c|c|c|c|c|c|c|c|}
\hline \multirow[b]{2}{*}{ entry } & \multirow[b]{2}{*}{ sample } & \multicolumn{3}{|c|}{$T_{\mathrm{g}}{ }^{a}\left({ }^{\circ} \mathrm{C}\right)$} & \multicolumn{2}{|c|}{$T_{\mathrm{m}}{ }^{a}\left({ }^{\circ} \mathrm{C}\right)$} & \multirow[b]{2}{*}{$-\Delta H_{\mathrm{m}}{ }^{b}\left(\mathrm{~J} \mathrm{~g}^{-1}\right)$} & \multirow[b]{2}{*}{$X_{c}^{c}(\%)$} \\
\hline & & PLA & PS & PI & PLA & SC & & \\
\hline 1 & $\mathrm{PS}_{18}-b-\mathrm{PDLA}_{10}$ & 48.9 & covered by $T_{\mathrm{cc}}$ & & 155.1 & & 25.5 & 28.4 \\
\hline 2 & $\mathrm{PI}_{22}-b-\mathrm{PLLA}_{10}$ & 48.8 & & -60.1 & 156.4 & & 31.5 & 30.2 \\
\hline 3 & $\mathrm{PS}_{18}-\mathrm{SC}_{10}-\mathrm{PI}_{22}$ & & 102.6 & -60.0 & & 219.9 & 46.3 & 45.1 \\
\hline 4 & $\mathrm{PS}_{18}$-b-PDLA ${ }_{3.6}$ & & 93.9 & & & & & \\
\hline 5 & $\mathrm{PI}_{22}-b-\mathrm{PLLA}_{3.6}$ & & & -60.5 & & & & \\
\hline 6 & $\mathrm{PS}_{18}-\mathrm{SC}_{3.6}-\mathrm{PI}_{22}$ & & 99.5 & -59.7 & & & & \\
\hline 7 & $\mathrm{PS}_{11}-b-\mathrm{PDLA}_{7}$ & & 90.2 & & 148.4 & & 14.7 & 15.1 \\
\hline 8 & $\mathrm{PI}_{12}-b-\mathrm{PLLA}_{7}$ & & & -63.5 & 154.0 & & 17.9 & 18.4 \\
\hline 9 & $\mathrm{PS}_{11}-\mathrm{SC}_{7}-\mathrm{PI}_{12}$ & & 98.5 & -60.1 & & 203.9 & 31.6 & 20.7 \\
\hline 10 & $\mathrm{PS}_{11}-b-\mathrm{PDLA}_{5}$ & 56.1 & 79.3 & & 128.0 & & 5.8 & \\
\hline 11 & $\mathrm{PI}_{12}-b-\mathrm{PLLA}_{5}$ & 57.5 & & -61.5 & 129.2 & & 9.7 & \\
\hline 12 & $\mathrm{PS}_{11}-\mathrm{SC}_{5}-\mathrm{PI}_{12}$ & & 91.4 & -60.6 & & 202.1 & 14.5 & 7.2 \\
\hline 13 & $\mathrm{PS}_{5.5}-b-\mathrm{PDLA}_{7}$ & 48 & & & 154.7 & & 21.6 & 24.1 \\
\hline 14 & $\mathrm{PI}_{6}-b-\mathrm{PLLA}_{7}$ & & & -61.7 & 152.3 & & 26.8 & 30.6 \\
\hline 15 & $\mathrm{PS}_{5.5}-\mathrm{SC}_{7}-\mathrm{PI}_{6}$ & & 70.7 & -60.9 & & 215.3 & 46.7 & 45.5 \\
\hline 16 & $\mathrm{PS}_{5.5^{-}} b-\mathrm{PDLA}_{5}$ & 65 & & & 141.3 & & 17.9 & 20.7 \\
\hline 17 & PI6- $b$-PLLA 5 & & & -61.8 & 143.4 & & 23.6 & 21.1 \\
\hline 18 & $\mathrm{PS}_{5.5}-\mathrm{SC}_{5}-\mathrm{PI}_{6}$ & & 65.0 & -62.0 & & 206.0 & 25.9 & 33.2 \\
\hline 19 & $\mathrm{PS}_{5.5}-b-\mathrm{PDLA}_{3.6}$ & & covered by $T_{c c}$ & & 149.4 & & 10.1 & 5.3 \\
\hline 20 & $\mathrm{PI}_{6}-b-\mathrm{PLLA}_{3.6}$ & & & -61.3 & 143.3 & & 12.1 & 4.9 \\
\hline 21 & $\mathrm{PS}_{5.5}-\mathrm{SC}_{3.6}-\mathrm{PI}_{6}$ & & 88 & -62.6 & & 206.9 & 14.7 & 23.3 \\
\hline
\end{tabular}

${ }^{a}$ Measured by DSC under a $\mathrm{N}_{2}$ atmosphere with heating rates of $10{ }^{\circ} \mathrm{C} \mathrm{min}^{-1}$. ${ }^{b}$ The melting enthalpy of PLA is normalized by its mass fraction. ${ }^{c}$ Determined by XRD with formula $X_{c}=$ area $_{\text {crystalline }} /$ area $_{\text {total }}$ on XRD spectra.

having a similar molecular weight. The higher the molecular weight of the amorphous block, the lower the $T_{\mathrm{m}}$ of the PLAs. This indicates that the crystalline and amorphous blocks are miscible in the melt, causing a dilution effect (the amorphous block behaves as the macromolecular solvent surrounding the PLA crystals in the melt) to the PLA crystals and therefore decrease the $T_{\mathrm{m}}$ of PLA. ${ }^{40,66}$

Double melting peaks are observed on several thermograms of PS- $b$-PDLA. The appearance of an endothermic double peak (for the relatively low-molecular-weight PLA copolymers) is attributed to a partial melting and recrystallization process during the measurement, which is a characteristic behavior of polyesters. $^{40}$

Upon the formation of SCs, the $T_{\mathrm{m}}$ of the PLA increases by $\sim 50-60{ }^{\circ} \mathrm{C}$ higher than the $T_{\mathrm{m}}$ of the PLA in the corresponding diblock copolymers, while for the SC derived from homopolymers, the increment of the $T_{\mathrm{m}}$ is $\sim 60-70{ }^{\circ} \mathrm{C}$. Moreover, the $\Delta H_{\mathrm{m}}$ of the PLA in PS-SC-PI samples (206 J $\mathrm{g}^{-1}<\Delta H_{\mathrm{m}, \mathrm{PS}-\mathrm{SC}-\mathrm{PI}}<219 \mathrm{~J} \mathrm{~g}^{-1}$ ) also increase, being significantly higher than the $\Delta H_{\mathrm{m}}$ of the PLA in PS- $b$-PDLA $\left(5 \mathrm{~J} \mathrm{~g}^{-1}<\Delta H_{\mathrm{m}, \text { PS- } b \text {-PDLA }}<26 \mathrm{~J} \mathrm{~g}^{-1}\right)$ and PI- $b$-PLLA $\left(5 \mathrm{~J} \mathrm{~g}^{-1}<\right.$ $\left.\Delta H_{\mathrm{m}, \mathrm{PI}-b \text {-PLLA }}<32 \mathrm{~J} \mathrm{~g}^{-1}\right)$. These results confirm the formation of a more rigid and denser crystal packing with a higher thermal stability. The improvement in the thermal stability is also reflected in the increase of $T_{\mathrm{g}}$ PS, and $T_{\mathrm{g}}$, $\mathrm{PI}$, which is $2-10$ ${ }^{\circ} \mathrm{C}$ higher than their $T_{\mathrm{g}} \mathrm{s}$ in block copolymers. Similar to the case of the diblock copolymers, the $T_{\mathrm{m}}$ and $\Delta H_{\mathrm{m}}$ of SCs tend to increase with the increase of the molecular weight of PLAs and decrease with the increase of the molecular weight of the amorphous blocks (e.g., entries 18 and 12 or entries 15 and 9).

XRD analysis was performed to confirm the formation of the SC. As shown in Figure 6, the block copolymers having PLA molecular weights of $\sim 5,7$, and $10 \mathrm{~kg} \mathrm{~mol}^{-1}$ exhibit the characteristic diffractions at $2 \theta$ of about 14.5, 16.8, 19.1, and $22.5^{\circ}$, which is in good agreement with the peaks of PLA homopolymers (Figure S7). These diffraction patterns correspond to the orthorhombic crystal lattice of the PLA $\alpha$ form. The $\alpha$-form is the most common polymorph for PLAs obtained from a melt or a dilute solution. ${ }^{67}$ Both homopolymers (Figure S7) and copolymers exhibit similar reflection patterns. Obviously, there are no changes in the unit cell of the PLA crystal in the block copolymers even though PS/PI amorphous blocks coexist in the system.

The PS-SC-PI samples exhibit the diffraction patterns of a triclinic crystal with $2 \theta$ peaks of around $11.8,20.5$, and $23.9^{\circ}$ and agreed well with the SC peaks obtained from homopolymers (Figure S7). SCs derived from $\mathrm{PS}_{18^{-b}-}$ $\mathrm{PDLA}_{3.6}, \mathrm{PI}_{22}-b-\mathrm{PLLA}_{3.6}, \mathrm{PS}_{11}-b-\mathrm{PDLA}_{5}$, and $\mathrm{P}_{12}-\mathrm{b}-\mathrm{PLLA}_{5}$ did not show clear peaks on $\mathrm{XRD}$, probably because their crystalline domains are trapped inside the amorphous matrix (the majority component).

The total degree of crystallinity $\left(X_{c}\right)$ of crystalline polymeric materials can be calculated from their XRD diffractograms. $X_{c}$ is defined as the ratio of the area of all crystalline peaks to the total area under the XRD peaks (crystalline + amorphous). Based on DSC and XRD results, both PS and PI segments are amorphous (Figure S8). Therefore, the $X_{c}$ of the diblock copolymers and their SCs obtained from XRD can be attributed to the $X_{c}$ of their PLA segments.

As can be seen in Figure 6 , the $X_{c}$ s of PS- $b$-PDLAs $\left(5 \%<X_{c}\right.$ $<25 \%)$, PI- $b$-PLLAs $\left(4 \%<X_{\mathrm{c}}<31 \%\right)$, and SCs $\left(7 \%<X_{\mathrm{c}}<\right.$ $46 \%)$ increase with the increase of the molecular weight of PLAs and decrease with the increase of the molecular weight of the amorphous blocks. The trend is similar to the trend of $\Delta H_{\mathrm{m}}$ of the PLA segment obtained by DSC. $\mathrm{PS}_{5.5}-\mathrm{SC}_{5}-\mathrm{PI}_{6}$, $\mathrm{PS}_{5.5}-\mathrm{SC}_{7}-\mathrm{PI}_{6}, \mathrm{PS}_{11}-\mathrm{SC}_{7}-\mathrm{PI}_{12}, \mathrm{PS}_{18}-\mathrm{SC}_{10}-\mathrm{PI}_{22}$, and their corresponding precursor diblock copolymers show sharp XRD peaks. This clearly indicates that the fraction of crystalline domains increases with the increase of the molecular weight of PLAs. In contrast, $\mathrm{PS}_{5.5}-\mathrm{SC}_{3.6}-\mathrm{PI}_{6}, \mathrm{PS}_{11}-\mathrm{SC}_{3.6}-\mathrm{PI}_{12}, \mathrm{PS}_{18}-$ 

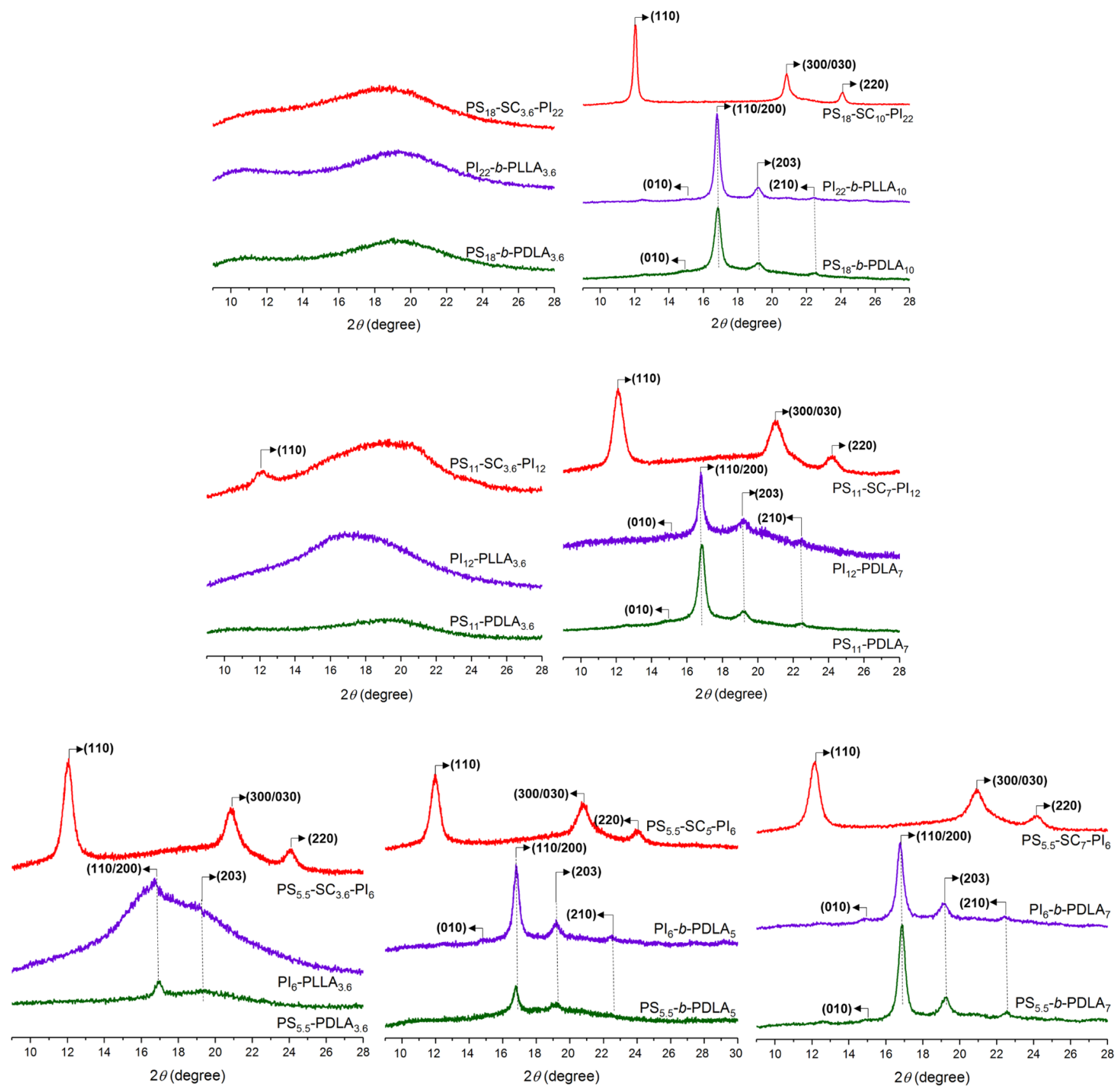

Figure 6. XRD diffractograms of the diblock copolymers and the corresponding SCs.

$\mathrm{SC}_{3.6}-\mathrm{PI}_{22}$, and their corresponding precursors exhibit weak/ no peak on XRD due to the lower PLA molecular weight (higher amorphous fractions). The overall $X_{c} s$ of PLA copolymers (Table 2) are lower than those in homopolymers (Table S2). As Michell et al. described, "generally, the copolymers require larger supercooling for crystallization than the homopolymers". ${ }^{40}$ Therefore, the presence of PS and PI (amorphous) blocks delay the crystallization process of PLA blocks in this type of melt miscible diblock copolymers.

Morphological Study of the SCs and Their Respective Precursors. All the films shown in Figure 7 were annealed at $180{ }^{\circ} \mathrm{C}$ for $5 \mathrm{~min}$ under vacuum before cooling to room temperature. The purpose of these preliminary AFM studies was to observe the adopted morphology under a short annealing time, similar to the sample preparation conditions prior to DSC and XRD measurements. In the case of the $\mathrm{PS}_{11^{-}}$
$b$-PDLA 7 precursor (Figure 7a), the image depicts islands due to the dewetting of the film to the substrate, indicating a disordered structure. Here, bright islands correspond to $\mathrm{PDLA}_{7}$ regions of about $30 \mathrm{~nm}$. The PDLA 7 block stands as islands on the free surface due to the commensurability effect between the initial film thickness and the bulk domain space, as mentioned in the previous study. ${ }^{68}$ Although PS and PDLA blocks have relatively similar surface energies and are expected to form the perpendicularly oriented cylindrical morphology, ${ }^{69}$ the island and hole formation is attributed to the fact that the polymer/substrate interface dominates the structure evolution. ${ }^{68}$ For the respective thin film of $\mathrm{PI}_{12}-b$ - $\mathrm{PLLA}_{7}$ (Figure $7 \mathrm{~b})$, the image is consistent with a weakly microphaseseparated film with a combination of lines and dots as cylindrical microdomains oriented perpendicular to the surface. Similar to the above precursor, the bright segment 

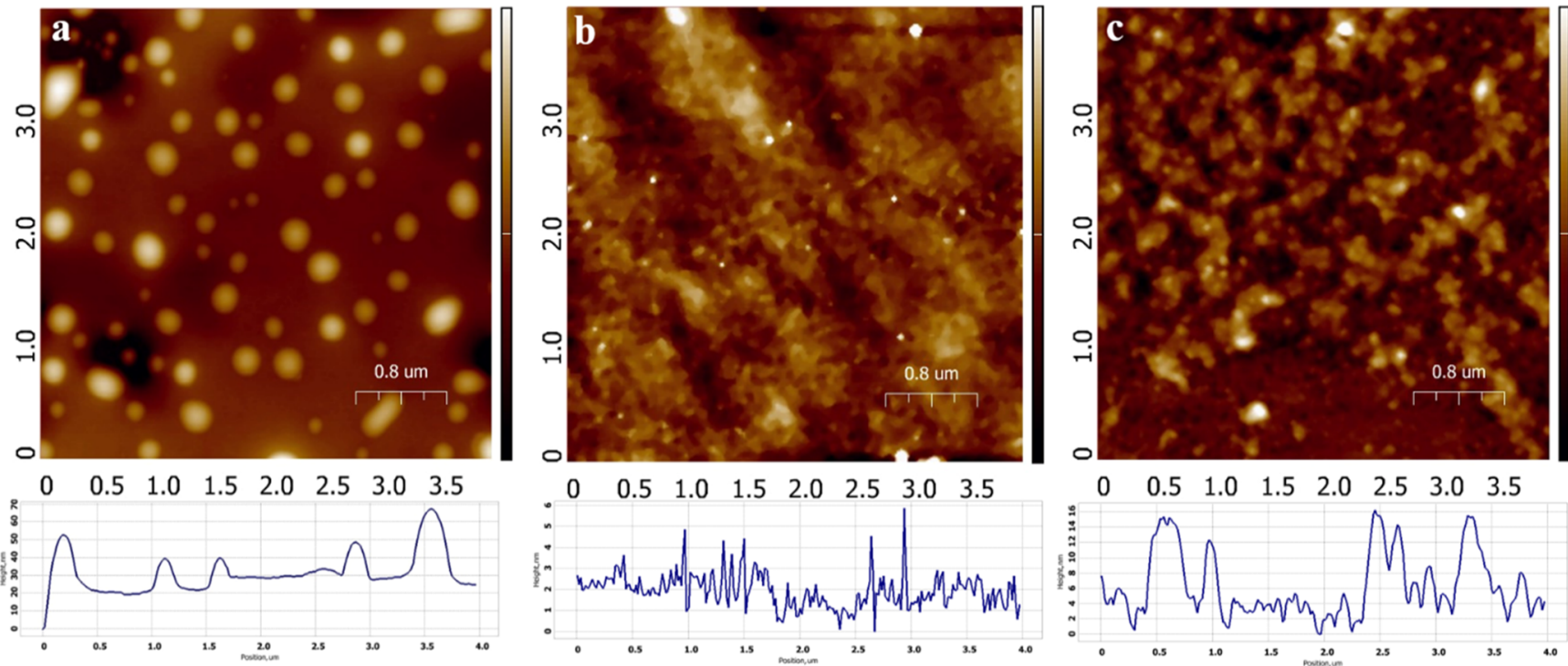

Figure 7. AFM height images and the corresponding line profiles of the thin films: (a) $\mathrm{PS}_{11}-b$-PDLA, , (b) $\mathrm{PI}_{12}-b$-PLLA P $_{7}$ and (c) corresponding $\mathrm{PS}_{11}-\mathrm{SC}_{7}-\mathrm{PI}_{12}$.

corresponds to the higher modulus block of crystalline PLLA compared to that of the dark region of elastomeric $\mathrm{PI}_{12}$.

The same film deposition and thermal treatment were applied to $\mathrm{PS}_{11}-\mathrm{SC}_{7}-\mathrm{PI}_{12}$. The surface area that is covered by bright spots and corresponds to the PLA domain is relatively smaller than that of the precursor's images due to the increased amorphous region of PS and PI. Here, stereocomplexed PLA chains are clearly deployed as a bright upper layer of PLA crystals on top of the sublayer, which mainly consists of the glassy PS and soft rubbery PI confinement. Here, PLA crystallization dominates the formation of a parallel-oriented cylindrical morphology. The cross-sectional profile indicates the relative height distance between the relief crystal domain and the amorphous underlayer domain. However, further study is needed to reveal the phase behavior of this complex noncovalent $\mathrm{PS}_{11}-\mathrm{SC}_{7}-\mathrm{PI}_{12}$ triblock terpolymer system, and the results will be presented in a forthcoming paper.

\section{CONCLUSIONS}

Well-defined PS- $b$-PDLA and PI- $b$-PLLA diblock copolymers were synthesized by combining an anionic polymerization high-vacuum technique with ROP; the molecular structure was confirmed by ${ }^{1} \mathrm{H}$ NMR and GPC analyses. The diblock copolymers were used to prepare non-covalent triblock terpolymers, PS-SC-PIs, via the stereocomplexation of PDLA and PLLA having an equivalent PLA molecular weight. FTIR, CD, DSC, and XRD spectroscopies confirmed the formation of linear non-covalent triblock terpolymers. Similar to PLA homopolymers, the thermal stability (reflected in $T_{\mathrm{g}}$, $T_{\mathrm{m}}, \Delta H_{\mathrm{m}}$, and $\left.X_{\mathrm{c}}\right)$ of diblock and triblock terpolymers increases with the increase of the molecular weight of the PLA segment in the copolymers. On the contrary, the thermal stability decreases with the increase of the molecular weight of PS and PI amorphous segments.

This study opens many routes for the synthesis of various well-defined complex macromolecular architectures of PLAbased SCs.

\section{ASSOCIATED CONTENT}

\section{s) Supporting Information}

The Supporting Information is available free of charge at https://pubs.acs.org/doi/10.1021/acs.macromol.1c02294.

Molecular characteristics of homopolymers; GPC, FTIR, $\mathrm{CD}, \mathrm{UV}, \mathrm{DSC}$, and XRD of homopolymers; and 2DDOSY NMR spectra of diblock copolymers (PDF)

\section{AUTHOR INFORMATION}

\section{Corresponding Author}

Nikos Hadjichristidis - Physical Sciences and Engineering Division, KAUST Catalysis Center, Polymer Synthesis Laboratory, King Abdullah University of Science and Technology (KAUST), Thuwal 23955, Saudi Arabia; (1) orcid.org/0000-0003-1442-1714; Phone: + 966-(0)128080789; Email: nikolaos.hadjichristidis@kaust.edu.sa

\section{Authors}

Viko Ladelta - Physical Sciences and Engineering Division, KAUST Catalysis Center, Polymer Synthesis Laboratory, King Abdullah University of Science and Technology (KAUST), Thuwal 23955, Saudi Arabia; 다. orcid.org/ 0000-0003-0596-7571

Konstantinos Ntetsikas - Physical Sciences and Engineering Division, KAUST Catalysis Center, Polymer Synthesis Laboratory, King Abdullah University of Science and Technology (KAUST), Thuwal 23955, Saudi Arabia; (1) orcid.org/0000-0002-9236-931X

George Zapsas - Physical Sciences and Engineering Division, KAUST Catalysis Center, Polymer Synthesis Laboratory, King Abdullah University of Science and Technology (KAUST), Thuwal 23955, Saudi Arabia; (1) orcid.org/ 0000-0003-3802-3550

Complete contact information is available at:

https://pubs.acs.org/10.1021/acs.macromol.1c02294

\section{Notes}

The authors declare no competing financial interest. 


\section{ACKNOWLEDGMENTS}

Research reported in this publication was supported by the King Abdullah University of Science and Technology (KAUST).

\section{REFERENCES}

(1) Bai, H.; Deng, S.; Bai, D.; Zhang, Q.; Fu, Q. Recent Advances in Processing of Stereocomplex-Type Polylactide. Macromol. Rapid Commun. 2017, 38, 1700454.

(2) Raquez, J.-M.; Habibi, Y.; Murariu, M.; Dubois, P. Polylactide (PLA)-based Nanocomposites. Prog. Polym. Sci. 2013, 38, 15041542.

(3) Nofar, M.; Sacligil, D.; Carreau, P. J.; Kamal, M. R.; Heuzey, M.C. Poly (lactic acid) blends: Processing, Properties and Applications. Int. J. Biol. Macromol. 2019, 125, 307-360.

(4) Lasprilla, A. J. R.; Martinez, G. A. R.; Lunelli, B. H.; Jardini, A. L.; Filho, R. M. Poly-Lactic Acid Synthesis for Application In Biomedical Devices - A review. Biotechnol. Adv. 2012, 30, 321-328.

(5) Armentano, I.; Bitinis, N.; Fortunati, E.; Mattioli, S.; Rescignano, N.; Verdejo, R.; Lopez-Manchado, M. A.; Kenny, J. M. Multifunctional nanostructured PLA Nmaterials for Packaging and Tissue Engineering. Prog. Polym. Sci. 2013, 38, 1720-1747.

(6) Lim, L.-T.; Auras, R.; Rubino, M. Processing technologies for Poly(lactic acid). Prog. Polym. Sci. 2008, 33, 820-852.

(7) Kale, G.; Kijchavengkul, T.; Auras, R.; Rubino, M.; Selke, S. E.; Singh, S. P. Compostability of Bioplastic Packaging Materials: An Overview. Macromol. Biosci. 2007, 7, 255-277.

(8) Auras, R.; Harte, B.; Selke, S. An Overview of Polylactides as Packaging Materials. Macromol. Biosci. 2004, 4, 835-864.

(9) Pretula, J.; Slomkowski, S.; Penczek, S. Polylactides-Methods of Synthesis and Characterization. Adv. Drug Delivery Rev. 2016, 107, $3-16$.

(10) Dechy-Cabaret, O.; Martin-Vaca, B.; Bourissou, D. Controlled Ring-Opening Polymerization of Lactide and Glycolide. Chem. Rev. 2004, 104, 6147-6176.

(11) Stanford, M. J.; Dove, A. P. Stereocontrolled Ring-Opening Polymerisation of Lactide. Chem. Soc. Rev. 2010, 39, 486-494.

(12) Tsuji, H.; Horii, F.; Hyon, S. H.; Ikada, Y. Stereocomplex Formation Between Enantiomeric Poly(Lactic Acid)S. 2. Stereocomplex Formation In Concentrated Solutions. Macromolecules 1991, 24, 2719-2724.

(13) Tsuji, H. Poly(lactide) Stereocomplexes: Formation, Structure, Properties, Degradation, and Applications. Macromol. Biosci. 2005, 5, 569-597.

(14) Ikada, Y.; Jamshidi, K.; Tsuji, H.; Hyon, S. H. Stereocomplex Formation Between Enantiomeric Poly(lactides). Macromolecules 1987, 20, 904-906.

(15) Zhang, J.; Sato, H.; Tsuji, H.; Noda, I.; Ozaki, Y. Infrared Spectroscopic Study of CH3 ‥ OC Interaction during Poly(L-lactide)/ Poly(D-lactide) Stereocomplex Formation. Macromolecules 2005, 38, $1822-1828$

(16) Zhang, J.; Sato, H.; Tsuji, H.; Noda, I.; Ozaki, Y. Differences in the $\mathrm{CH} 3 \cdots$ OC Interactions Among Poly(L-lactide), Poly(L-lactide)/ Poly(D-lactide) Stereocomplex, and Poly(3-Hydroxybutyrate) Studied by Infrared Spectroscopy. J. Mol. Struct. 2005, 735-736, 249257.

(17) Zhou, W.; Wang, K.; Wang, S.; Yuan, S.; Chen, W.; Konishi, T.; Miyoshi, T. Stoichiometry and Packing Structure of Poly(lactic acid) Stereocomplex as Revealed by Solid-State NMR and ${ }^{13} \mathrm{C}$ Isotope Labeling. ACS Macro Lett. 2018, 7, 667-671.

(18) Okihara, T.; Tsuji, M.; Kawaguchi, A.; Katayama, K.-I.; Tsuji, H.; Hyon, S.-H.; Ikada, Y. Crystal Structure of Stereocomplex of Poly(L-lactide) and Poly(D-lactide). J. Macromol. Sci., Part B: Phys. 1991, 30, 119-140.

(19) Tsuji, H.; Fukui, I. Enhanced Thermal Stability of Poly(lactide)s in the Melt by Enantiomeric Polymer Blending. Polymer 2003, 44, 2891-2896.
(20) Tsuji, H. In Vitro Hydrolysis of Blends From Enantiomeric Poly(lactide)S Part 1. Well-Stereo-Complexed Blend and NonBlended Films. Polymer 2000, 41, 3621-3630.

(21) de Jong, S. J.; De Smedt, S. C.; Demeester, J.; van Nostrum, C. F.; Kettenes-van den Bosch, J. J.; Hennink, W. E. Biodegradable Hydrogels Based on Stereocomplex Formation Between Lactic Acid Oligomers Grafted to Dextran. J. Controlled Release 2001, 72, 47-56.

(22) Tsuji, H. In Vitro Hydrolysis of Blends from Enantiomeric Poly(lactide)s Part 1. Well-Stereo-Complexed Blend and NonBlended Films. Polymer 2000, 41, 3621-3630.

(23) Grancharov, G.; Coulembier, O.; Surin, M.; Lazzaroni, R.; Dubois, P. Stereocomplexed Materials Based on Poly(3-hexylthiophene)-b-poly(lactide) Block Copolymers: Synthesis by Organic Catalysis, Thermal Properties, and Microscopic Morphology. Macromolecules 2010, 43, 8957-8964.

(24) Tsuji, H. Poly(lactic acid) stereocomplexes: A Decade of Progress. Adv. Drug Delivery Rev. 2016, 107, 97-135.

(25) Worch, J. C.; Prydderch, H.; Jimaja, S.; Bexis, P.; Becker, M. L.; Dove, A. P. Stereochemical Enhancement of Polymer Properties. Nat. Rev. Chem. 2019, 3, 514-535.

(26) Kang, N.; Perron, M.-È.; Prud'homme, R. E.; Zhang, Y.; Gaucher, G.; Leroux, J.-C. Stereocomplex Block Copolymer Micelles: Core-Shell Nanostructures with Enhanced Stability. Nano Lett. 2005, $5,315-319$.

(27) Bishara, A.; Kricheldorf, H. R.; Domb, A. J. Stereocomplexes of Triblock Poly(lactide- PEG2000-lactide) as Carrier of Drugs. Macromol. Symp. 2005, 225, 17-30.

(28) Chen, L.; Xie, Z.; Hu, J.; Chen, X.; Jing, X. Enantiomeric PLAPEG Block Copolymers and Their Stereocomplex Micelles Used as Rifampin Delivery. J. Nanopart. Res. 2007, 9, 777-785.

(29) Rathi, S.; Chen, X.; Coughlin, E. B.; Hsu, S. L.; Golub, C. S.; Tzivanis, M. J. Toughening Semicrystalline Poly(lactic Acid) by Morphology Alteration. Polymer 2011, 52, 4184-4188.

(30) Ando, H.; Oshima, M.; Nakayama, Y.; Nakayama, A. Polyethylene Glycol-Solvolyzed Poly-(L)-lactic Acids and Their Stereocomplexes with Poly-(D)-lactic Acid. Polym. Degrad. Stab. 2013, 98, 958-962.

(31) Liu, Y.; Shao, J.; Sun, J.; Bian, X.; Feng, L.; Xiang, S.; Sun, B.; Chen, Z.; Li, G.; Chen, X. Improved mechanical and Thermal Properties of PLLA by Solvent Blending with PDLA-b-PEG-b-PDLA. Polym. Degrad. Stab. 2014, 101, 10-17.

(32) Song, Y.; Wang, D.; Jiang, N.; Gan, Z. Role of PEG Segment in Stereocomplex Crystallization for PLLA/PDLA-b-PEG-b-PDLA Blends. ACS Sustainable Chem. Eng. 2015, 3, 1492-1500.

(33) Tacha, S.; Saelee, T.; Khotasen, W.; Punyodom, W.; Molloy, R.; Worajittiphon, P.; Meepowpan, P.; Manokruang, K. Stereocomplexation of PLL/PDL-PEG-PDL Blends: Effects of Blend Morphology on Film Toughness. Eur. Polym. J. 2015, 69, 308-318.

(34) Shirahama, H.; Ichimaru, A.; Tsutsumi, C.; Nakayama, Y.; Yasuda, H. Characteristics of the Biodegradability and Physical Properties of Stereocomplexes Between Poly(L-Lactide) and Poly(Dlactide) Copolymers. J. Polym. Sci., Part A: Polym. Chem. 2005, 43, 438-454.

(35) Wanamaker, C. L.; Bluemle, M. J.; Pitet, L. M.; O’Leary, L. E.; Tolman, W. B.; Hillmyer, M. A. Consequences of Polylactide Stereochemistry on the Properties of Polylactide-PolymenthidePolylactide Thermoplastic Elastomers. Biomacromolecules 2009, 10, 2904-2911.

(36) Wanamaker, C. L.; Tolman, W. B.; Hillmyer, M. A. Poly(Dlactide $)$-Poly(menthide)-Poly(D-lactide) Triblock Copolymers as Crystal Nucleating Agents for Poly(L-lactide). Macromol. Symp. 2009, 283-284, 130-138.

(37) Stoyanova, N.; Mincheva, R.; Paneva, D.; Manolova, N.; Dubois, P.; Rashkov, I. Electrospun Non-Woven Mats from Stereocomplex Between High Molar Mass Poly(L-lactide) and Poly(D-lactide)-b-Poly(butylene succinate) Copoly(ester urethane)S. Eur. Polym. J. 2012, 48, 1965-1975.

(38) Spasova, M.; Mespouille, L.; Coulembier, O.; Paneva, D.; Manolova, N.; Rashkov, I.; Dubois, P. Amphiphilic Poly(D- or L- 
lactide)-b-poly(N,N-dimethylamino-2-ethyl methacrylate) Block Copolymers: Controlled Synthesis, Characterization, and Stereocomplex Formation. Biomacromolecules 2009, 10, 1217-1223.

(39) Spasova, M.; Manolova, N.; Paneva, D.; Mincheva, R.; Dubois, P.; Rashkov, I.; Maximova, V.; Danchev, D. Polylactide Stereocomplex-Based Electrospun Materials Possessing Surface with Antibacterial and Hemostatic Properties. Biomacromolecules 2010, 11, 151-159.

(40) Michell, R. M.; Müller, A. J.; Spasova, M.; Dubois, P.; Burattini, S.; Greenland, B. W.; Hamley, I. W.; Hermida-Merino, D.; Cheval, N.; Fahmi, A. Crystallization and Stereocomplexation Behavior of Poly(D- and L-lactide)-b-poly(N,N-dimethylamino-2-ethyl methacrylate) Block Copolymers. J. Polym. Sci., Part B: Polym. Phys. 2011, 49, 1397-1409.

(41) Wolf, F. K.; Hofmann, A. M.; Frey, H. Poly(isoglycerol methacrylate)-b-poly(D or L-lactide) Copolymers: A Novel Hydrophilic Methacrylate as Building Block for Supramolecular Aggregates. Macromolecules 2010, 43, 3314-3324.

(42) Fan, X.; Wang, Z.; Yuan, D.; Sun, Y.; Li, Z.; He, C. Novel Linear-Dendritic-Like Amphiphilic Copolymers: Synthesis And SelfAssembly Characteristics. Polym. Chem. 2014, 5, 4069-4075.

(43) Uehara, H.; Karaki, Y.; Wada, S.; Yamanobe, T. StereoComplex Crystallization of Poly(lactic acid)s in Block-Copolymer Phase Separation. ACS Appl. Mater. Interfaces 2010, 2, 2707-2710.

(44) Schmidt, S. C.; Hillmyer, M. A. Synthesis and Characterization of Model Polyisoprene-Polylactide Diblock Copolymers. Macromolecules 1999, 32, 4794-4801.

(45) Frick, E. M.; Hillmyer, M. A. Synthesis and Characterization of Polylactide-Block-Polyisoprene-Block-Polylactide Triblock Copolymers: New Thermoplastic Elastomers Containing Biodegradable Segments. Macromol. Rapid Commun. 2000, 21, 1317-1322.

(46) Sun, L.; Pitto-Barry, A.; Kirby, N.; Schiller, T. L.; Sanchez, A. M.; Dyson, M. A.; Sloan, J.; Wilson, N. R.; O’Reilly, R. K.; Dove, A. P. Structural Reorganization Of Cylindrical Nanoparticles Triggered by Polylactide Stereocomplexation. Nat. Commun. 2014, 5, 5746.

(47) Ho, R.-M.; Chiang, Y.-W.; Tsai, C.-C.; Lin, C.-C.; Ko, B.-T.; Huang, B.-H. Three-Dimensionally Packed Nanohelical Phase in Chiral Block Copolymers. J. Am. Chem. Soc. 2004, 126, 2704-2705.

(48) Chiang, Y.-W.; Ho, R.-M.; Ko, B.-T.; Lin, C.-C. Springlike Nanohelical Structures in Chiral Block Copolymers. Angew. Chem., Int. Ed. 2005, 44, 7969-7972.

(49) Ho, R.-M.; Chiang, Y.-W.; Chen, C.-K.; Wang, H.-W.; Hasegawa, H.; Akasaka, S.; Thomas, E. L.; Burger, C.; Hsiao, B. S. Block Copolymers with a Twist. J. Am. Chem. Soc. 2009, 131, 1853318542.

(50) Tseng, W.-H.; Chen, C.-K.; Chiang, Y.-W.; Ho, R.-M.; Akasaka, S.; Hasegawa, H. Helical Nanocomposites from Chiral Block Copolymer Templates. J. Am. Chem. Soc. 2009, 131, 1356-1357.

(51) Chiang, Y.-W.; Ho, R.-M.; Burger, C.; Hasegawa, H. Helical Assemblies from Chiral Block Copolymers. Soft Matter 2011, 7, 9797-9803.

(52) Bhaumik, S.; Ntetsikas, K.; Hadjichristidis, N. Noncovalent Supramolecular Diblock Copolymers: Synthesis and Microphase Separation. Macromolecules 2020, 53, 6682-6689.

(53) Hadjichristidis, N.; Iatrou, H.; Pispas, S.; Pitsikalis, M. Anionic Polymerization: High Vacuum Techniques. J. Polym. Sci., Part A: Polym. Chem. 2000, 38, 3211-3234.

(54) Uhrig, D.; Mays, J. W. Experimental Techniques in Highvacuum Anionic Polymerization. J. Polym. Sci., Part A: Polym. Chem. 2005, 43, 6179-6222.

(55) Quirk, R. P.; Ma, J.-J. Characterization of the functionalization reaction product of poly(styryl)lithium with ethylene oxide. J. Polym. Sci., Part A: Polym. Chem. 1988, 26, 2031-2037.

(56) Sharma, S.; Ntetsikas, K.; Ladelta, V.; Bhaumik, S.; Hadjichristidis, N. Well-defined Cyclic Polymer Synthesis via An Efficient Etherification-Based Bimolecular Ring-Closure Strategy. Polym. Chem. 2021, 12, 6616-6625.

(57) Worsfold, D. J.; Bywater, S. Lithium Alkyl Initiated Polymerization of Isoprene. Effect of Cis/Trans Isomerization of Organo- lithium Compounds on Polymer Microstructure. Macromolecules 1978, 11, 582-586.

(58) Ladelta, V.; Zapsas, G.; Abou-hamad, E.; Gnanou, Y.; Hadjichristidis, N. Tetracrystalline Tetrablock Quarterpolymers: Four Different Crystallites under the Same Roof. Angew. Chem., Int. Ed. 2019, 58, 16267-16274.

(59) Chang, Y.; Chen, Z.; Yang, Y. Benign Fabrication of Fully Stereocomplex Polylactide with High Molecular Weights via a Thermally Induced Technique. ACS Omega 2018, 3, 7979-7984.

(60) Ge, H.; Zhang, F.; Huang, H.; He, T. Interplay between Stereocomplexation and Microphase Separation in PS-b-PLLA-bPDLA Triblock Copolymers. Macromolecules 2019, 52, 1004-1012.

(61) Sarasua, J.-R.; Rodríguez, N. L.; Arraiza, A. L.; Meaurio, E. Stereoselective Crystallization and Specific Interactions in Polylactides. Macromolecules 2005, 38, 8362-8371.

(62) Pan, P.; Yang, J.; Shan, G.; Bao, Y.; Weng, Z.; Cao, A.; Yazawa, K.; Inoue, Y. Temperature-Variable FTIR and Solid-State ${ }^{13} \mathrm{C}$ NMR Investigations on Crystalline Structure and Molecular Dynamics of Polymorphic Poly(L-lactide) and Poly(L-lactide)/Poly(D-lactide) Stereocomplex. Macromolecules 2012, 45, 189-197.

(63) Blanchard, L.-P.; Hesse, J.; Malhotra, S. L. Effect of Molecular Weight on Glass Transition by Differential Scanning Calorimetry. Can. J. Chem. 1974, 52, 3170-3175.

(64) Widmaier, J. M.; Meyer, G. C. Glass Transition Temperature of Anionic Polyisoprene. Macromolecules 1981, 14, 450-452.

(65) Ho, R.-M.; Chen, C.-K.; Chiang, Y.-W.; Ko, B.-T.; Lin, C.-C. Tubular Nanostructures from Degradable Core-Shell Cylinder Microstructures in Chiral Diblock Copolymers. Adv. Mater. 2006, $18,2355-2358$

(66) Strobl, G. Crystallization and melting of bulk polymers: New observations, Conclusions and A Thermodynamic Scheme. Prog. Polym. Sci. 2006, 31, 398-442.

(67) Miyata, T.; Masuko, T. Morphology of Poly(L-lactide) Solution-Grown Crystals. Polymer 1997, 38, 4003-4009.

(68) Chen, D.; Gong, Y.; Huang, H.; He, T.; Zhang, F. Competition of Lamellar Orientation in Thin Films of a Symmetric Poly(styrene)b-poly(1-lactide) Diblock Copolymer in Melt State. Macromolecules 2007, 40, 6631-6637.

(69) Olayo-Valles, R.; Guo, S.; Lund, M. S.; Leighton, C.; Hillmyer, M. A. Perpendicular Domain Orientation in Thin Films of Polystyrene-Polylactide Diblock Copolymers. Macromolecules 2005, 38, 10101-10108. 